NBER WORKING PAPER SERIES

\title{
COSTLY EXTERNAL FINANCE: IMPLICATIONS FOR CAPITAL MARKETS ANOMALIES
}

\author{
Dongmei Li \\ Lu Zhang \\ Working Paper 14342 \\ http://www.nber.org/papers/w14342 \\ NATIONAL BUREAU OF ECONOMIC RESEARCH \\ 1050 Massachusetts Avenue \\ Cambridge, MA 02138 \\ September 2008
}

We acknowledge helpful comments from Espen Eckbo, Gerald Garvey, Rick Green, Han Hong, Erica X. N. Li, Tyler Shumway, Neng Wang, Wei Xiong, Hong Yan (discussant), and other seminar participants at Hanqing Advanced Institute of Economics and Finance at Renmin University of China, the 2008 China International Conference in Finance, and the 2008 UBC PH\&N Summer Finance Conference. Parts of this paper were completed while Lu Zhang was visiting Hanqing Advanced Institute of Economics and Finance at Renmin University of China, whose hospitality is gratefully acknowledged. An earlier version of the paper was circulated under the title "Costly external equity: Implications for asset pricing anomalies." We are responsible for all the remaining errors. The views expressed herein are those of the author(s) and do not necessarily reflect the views of the National Bureau of Economic Research.

NBER working papers are circulated for discussion and comment purposes. They have not been peerreviewed or been subject to the review by the NBER Board of Directors that accompanies official NBER publications.

(C) 2008 by Dongmei Li and Lu Zhang. All rights reserved. Short sections of text, not to exceed two paragraphs, may be quoted without explicit permission provided that full credit, including $\odot$ notice, is given to the source. 
Costly External Finance: Implications for Capital Markets Anomalies

Dongmei Li and Lu Zhang

NBER Working Paper No. 14342

September 2008, Revised May 2009

JEL No. G12,G14

\begin{abstract}
$\underline{\text { ABSTRACT }}$
In a frictionless world, investment is perfectly elastic to changes in the discount rate. With financial frictions, investment is less elastic, meaning that a given magnitude of change in investment is associated with a higher magnitude of change in the discount rate. Equivalently, investment is a more powerful predictor of future stock returns. Consistent with this prediction, we document that the asset growth, external finance, and accrual anomalies in the cross-section of stock returns are much stronger in financially more constrained firms than in financially less constrained firms. Further tests show that this effect of financial constraints is distinct from the effect of financial distress and the effect of limits of arbitrage on the magnitude of the anomalies.
\end{abstract}

\author{
Dongmei Li \\ University of California, San Diego \\ Otterson Hall, Room 3S149 \\ 9500 Gilman Dr. \#0553 \\ La Jolla, CA 92093 \\ dongmei@ucsd.edu \\ Lu Zhang \\ Finance Department \\ Stephen M. Ross School of Business \\ University of Michigan \\ 701 Tappan Street, R 4336 \\ Ann Arbor, MI 48109-1234 \\ and NBER \\ zhanglu@bus.umich.edu
}




\section{Introduction}

Capital markets anomalies are empirical relations between average stock returns and firm characteristics, relations that cannot be explained by the Sharpe (1964) and Lintner (1965) Capital Asset Pricing Model (CAPM). Over the past two decades, anomalies have become increasingly important for estimating expected returns in asset allocation and investment management and for estimating costs of capital in capital budgeting and security valuation. And understanding the economic sources of anomalies is one of the most important questions in capital markets research.

We study how financial constraints affect the magnitude of capital markets anomalies. Our main message is that the asset growth, external finance, and accrual anomalies tend to be stronger in financially more constrained firms than in financially less constrained firms.

Using bond ratings to measure financial constraints, we find that in the unconstrained subsample consisting of firms whose corporate bonds are rated, the value-weighted average return, CAPM alpha, and Fama-French (1993) three-factor alpha for the high-minus-low asset growth portfolio are $-0.32 \%,-0.45 \%$, and $-0.03 \%$ per month. These estimates are substantially lower in magnitude than their counterparts, $-0.72 \%,-0.79 \%$, and $-0.47 \%$, respectively, in the constrained subsample consisting of firms whose corporate bonds are not rated. And the differences across the constrained and unconstrained subsamples are all more than 2.4 standard errors from zero. The basic results are robust with respect to using equal-weighted returns and alternative financial constraints measures.

The effect of net stock issues (a measure of external finance) also is stronger in more constrained firms. The value-weighted average return, CAPM alpha, and Fama-French alpha of the high-minus-low net stock issues portfolio are $-0.48 \%,-0.63 \%$, and $-0.44 \%$ per month in the low $W W$-index (least constrained) tercile. These estimates are more than halved in magnitude relative to their counterparts, $-1.34 \%,-1.60 \%$, and $-1.29 \%$, respectively, in the high $W W$-index (most constrained) tercile. And the differences across the extreme terciles are all more than 3.6 standard errors from zero. The basic results are robust with respect to using equal-weighted returns and to 
using payout ratio or bond ratings to measure financial constraints.

The accrual effect is stronger in more constrained firms. The equal-weighted average return, CAPM alpha, and Fama-French alpha of the high-minus-low accrual portfolio are $-0.34 \%,-0.37 \%$, and $-0.35 \%$ per month in the high payout ratio (least constrained) tercile, which are more than halved in magnitude compared to their counterparts, $-0.79 \%,-0.82 \%$, and $-0.75 \%$, respectively, in the low payout ratio (most constrained) tercile. The differences are more than 2.9 standard errors from zero. Although going in the same direction, the value-weighted results are insignificant.

We motivate our empirical analysis within a simple $q$-theory model in the spirit of Cochrane (1991). The economic intuition is fairly simple. In a frictionless world, investment is perfectly elastic to changes in the discount rate, meaning that a small change in the discount rate is associated with an infinite magnitude of change in investment. With financial frictions, investment entails financing costs, causing investment to be less elastic to changes in the discount rate. The more financially constrained a firm is, the less elastic the firm's investment will be in response to changes in the discount rate. Equivalently, the more financially constrained the firm is, a given change in investment of the firm will correspond to a higher magnitude of change in the discount rate, meaning that investment is a more powerful predictor of future returns. This elasticity mechanism applies to cross-sectional return predictability associated with asset growth, net stock issues, and accruals because these variables are all closely connected with capital investment.

Financial constraints and financial distress are different, albeit related, concepts. Financial constraints are frictions that prevent a firm from funding all desired investments, while financial distress is situations where cash flow is insufficient to cover current obligations. To disentangle the effect of financial constraints from that of financial distress, we study how the magnitude of the anomalies varies across subsamples split jointly by measures of financial constraints and financial distress. Using Ohlson's (1980) O-score and Campbell, Hilscher, and Szilagyi's (2008) failure probability to measure financial distress, we find that financial distress does not subsume financial 
constraints, but that financial constraints often dominate financial distress in our multivariate tests.

Another alternative hypothesis that we explore is the limits to arbitrage hypothesis. Anomalies can persist if the costs of arbitrage outweigh the benefits of arbitrage aimed to exploit the anomalies (e.g., Shleifer and Vishny (1997)). This hypothesis predicts that anomalies should be stronger in firms with more limits to arbitrage. Empirically, we find that measures of financial constraints are indeed correlated with proxies for limits to arbitrage such as dollar trading volume and idiosyncratic stock volatility. More important, although these proxies affect the magnitude of anomalies, their effect does not subsume, and is often subsumed by, the effect of financial constraints.

Our work adds to the literature that explores the interaction between capital investment and asset prices. Cochrane (1991) shows that investment is a strong predictor of stock market returns. Cochrane (1996) uses returns on physical investment as factors to price the cross section of returns. Lettau and Ludvigson (2002) use $q$-theory to study the impact of time-varying risk premiums on aggregate investment. Anderson and Garcia-Feijóo (2006) document that investment growth classifies firms into size and book-to-market portfolios. Whited and Wu (2006) construct an index of financial constraints via structural estimation and find that more constrained firms earn insignificantly higher average returns than less constrained firms. Xing (2008) shows that an investment growth factor can explain the value effect as well as Fama and French's (1993) value factor. Hahn and Lee (2009) study the effect of debt capacity on stock returns across constrained and unconstrained samples. None of these papers examine the impact of financial constraints on the magnitude of anomalies.

The rest of the paper is organized as follows. We develop testable hypotheses in Section 2, describe our sample in Section 3, present main empirical results in Section 4, and conclude in Section 5.

\section{Hypothesis Development}

We first derive the relation between financial constraints and cross-sectional return predictability associated with investment in a simple model. Based on the model's predictions, we develop 
testable hypotheses to guide our subsequent empirical analysis.

\subsection{A Simple $q$-theory Model with Costly External Finance}

We incorporate costly external finance into the $q$-theory framework in the spirit of Cochrane (1991). The model is deliberately designed to be conceptually simple and analytically tractable, but the central economic insight should hold in more general settings.

There are two periods, 0 and 1, and heterogeneous firms, indexed by $j$. Firms use capital and costlessly adjustable inputs to produce a perishable good. The levels of these inputs are chosen each period to maximize the firms' operating profits, defined as revenues minus the expenditures on these inputs. Firm $j$ 's operating profits are given by $\pi k_{j 0}$ in period 0 and $\pi k_{j 1}$ in period 1 , in which $\pi$ is the long-term average return on assets, which is time-invariant and constant across firms. Allowing $\pi$ to vary over time and across firms does not change the basic insights. $k_{j 0}$ and $k_{j 1}$ are firm $j$ 's capital in periods 0 and 1 , respectively. The operating-profits function exhibits constant returns to scale, meaning that $\pi$ is both the marginal product of capital and the average product of capital. Taking the operating profits as given, firms choose optimal investment to maximize their market value.

Firm $j$ starts with capital stock, $k_{j 0}$, invests in period 0 , and produces in both periods. Firm $j$ exits at the end of period 1 with a liquidation value of $(1-\delta) k_{j 1}$, in which $\delta$ is the rate of capital depreciation. Capital evolves as $k_{j 1}=i_{j}+(1-\delta) k_{j 0}$, in which $i$ is capital investment. We model financial constraints following Kaplan and Zingales (1997). When firm $j$ 's investment demand, $i_{j}$, is higher than its internal funds, $\pi k_{j 0}$, we assume that the firm covers the shortfall with external finance, $e_{j}$, defined as $\left(i_{j}-\pi k_{j 0}\right) \chi_{\left\{i_{j}>\pi k_{j 0}\right\}}$, in which $\chi_{\{\cdot\}}$ is an indicator function that takes the value of one if the event described in $\{\cdot\}$ is true, and otherwise takes the value of zero. When raising external funds, $e_{j}>0$, the firm incurs quadratic financing costs of $(\lambda / 2)\left(e_{j} / k_{j 0}\right)^{2} k_{j 0}$. As in Kaplan and Zingales, we use the constant parameter $\lambda>0$ to capture the degree of financial constraints: Firms with higher $\lambda$ are more constrained and firms with lower $\lambda$ are less constrained. The financing-cost function is increasing and convex in $e_{j}$ and decreasing in $k_{j 0}$. 
Firm $j$ has a gross discount rate, denoted $r_{j}$. The discount rate varies across firms due to, for example, firm-specific loadings on macroeconomic risk factors. The firm chooses $k_{j 1}$ to maximize its market value at the beginning of period 0 :

$\max _{\left\{k_{j 1}\right\}} \pi k_{j 0}-k_{j 1}+(1-\delta) k_{j 0}-\frac{\lambda}{2}\left(\frac{k_{j 1}-(1-\delta) k_{j 0}-\pi k_{j 0}}{k_{j 0}}\right)^{2} k_{j 0} \chi_{\left\{i_{j}>\pi k_{j 0}\right\}}+\frac{1}{r_{j}}\left(\pi k_{j 1}+(1-\delta) k_{j 1}\right)$

The market value of firm $j$ is the sum of period 0's free cash flow, $\pi k_{j 0}-i_{j}-(\lambda / 2)\left(e_{j} / k_{j 0}\right)^{2} k_{j 0}$, and the discounted value of date 1's cash flow, $\left(\pi k_{j 1}+(1-\delta) k_{j 1}\right) / r_{j}$. In this two-period setup, the firm does not invest in the second period, meaning that date 1's cash flow is simply the sum of the operating profits and the liquidation value of the capital.

The tradeoff of firm $j$ when making investment decisions is simple: Foregoing free cash flows today in exchange for higher free cash flows tomorrow. Setting the first-order derivative of the objective function with respect to $k_{j 1}$ to zero yields:

$$
r_{j}=\frac{\pi+1-\delta}{1+\lambda\left(i_{j} / k_{j 0}-\pi\right) \chi_{\left\{i_{j} / k_{j 0}>\pi\right\}}}
$$

This optimality condition is intuitive. The numerator in the right-hand side of equation (1) is the marginal benefit of investment, $\pi+1-\delta$, including the marginal product of capital, $\pi$, and the marginal liquidation value of capital, $1-\delta$. The denominator is the marginal cost of investment that includes the marginal purchasing cost of investment, unity, and the marginal financing cost, $\lambda\left(i_{j} / k_{j 0}-\pi\right)$, if the firm is financially constrained $\left(\lambda>0\right.$ and $\left.i_{j} / k_{j 0}>\pi\right)$. Because the marginal benefit of investment is in date 1's dollar terms and the marginal cost of investment is in date 0's dollar terms, the optimality condition says that the marginal benefit of investment, discounted in date 0's dollar terms, should be equal to the marginal cost of investment. Equivalently, the investment return (the ratio of the marginal benefit of investment divided by the marginal cost of investment) should equal the discount rate, as in Cochrane (1991).

We are interested in knowing how $\lambda$ affects the investment effect in cross-sectional returns. To 
simplify notations, we only analyze constrained firms with $i_{j} / k_{j 0}>\pi$. We can then drop the indicator function, $\chi_{\left\{i_{j} / k_{j 0}>\pi\right\}}$, from equation (1). Differentiating this equation with respect to $i_{j}$ yields:

$$
\frac{\partial r_{j}}{\partial i_{j}}=-\frac{\lambda}{k_{j 0}} \frac{\pi+1-\delta}{\left[1+\lambda\left(i_{j} / k_{j 0}-\pi\right)\right]^{2}}<0
$$

As such, investment predicts returns with a negative sign as in Cochrane (1991). And the magnitude of $\partial r_{j} / \partial i_{j}$ captures the magnitude of the investment effect. To see how this magnitude varies with costly external finance, we differentiate the absolute value of $\partial r_{j} / \partial i_{j}$ with respect to $\lambda$ to obtain:

$$
\partial\left|\frac{\partial r_{j}}{\partial i_{j}}\right| / \partial \lambda=\frac{(\pi+1-\delta)\left[1-\lambda\left(i_{j} / k_{j 0}-\pi\right)\right]}{k_{j 0}\left[1+\lambda\left(i_{j} / k_{j 0}-\pi\right)\right]^{3}}
$$

which is positive as long as $1-\lambda\left(i_{j} / k_{j 0}-\pi\right)$ or $1-\lambda\left(e_{j} / k_{j 0}\right)>0$.

This condition is empirically plausible, as demonstrated in a simple back-of-the-envelope calculation. The average investment-to-capital ratio is about $12 \%$ per annum or $1 \%$ per month. Suppose $50 \%$ of the investment is financed by external funds, the average new equity-to-capital ratio is then $0.50 \%$ per month, meaning that $1-\lambda\left(e_{j} / k_{j 0}\right)>0$ holds as long as $\lambda<200$ in monthly frequency. This restriction is quite weak. With an average new equity-to-capital ratio of $0.50 \%$, $\lambda=200$ means that financing costs are as high as $50 \%$ of the proceeds raised from external funds: $\left[(\lambda / 2)\left(e_{j} / k_{j 0}\right)^{2} k_{j 0}\right] / e_{j}=(\lambda / 2)\left(e_{j} / k_{j 0}\right)=(200 / 2) \times 0.50 \%=50 \%$. In summary:

Central Prediction. Under weak conditions, the magnitude of the investment effect is stronger in more constrained firms than that in less constrained firms.

Figure 1 provides a numerical example of the economic mechanism at work. We let the investment-to-capital ratio vary from $15 \%$ to $20 \%$ per annum with $\delta=0$ and $\pi=15 \%$ per annum. We plot the monthly $r_{j}$ calculated from equation (1) against monthly $i_{j} / k_{j 0}$ for three different values of $\lambda$ : 0 (the solid line), 5 (the dashed line), and 10 (the dashdot line). The discount rate-investment relation becomes steeper as we gradually increase the cost parameter of external finance, $\lambda$. In particular, when firms are unconstrained financially, $\lambda=0$, the discount rate, $r_{j}$, is flat in $i_{j} / k_{j 0}$. 
Figure 1 : The Discount Rate versus Investment-to-Capital in the Simple $q$-theory Model

We plot the discount rate, $r_{j}$, against the investment-to-capital ratio, $i_{j} / k_{j 0}$, based on the functional form:

$$
r_{j}=\frac{\pi+1-\delta}{1+\lambda\left(i_{j} / k_{j 0}-\pi\right) \chi_{\left\{i_{j} / k_{j 0}>\pi\right\}}}
$$

We plot the relation for three values of the financing cost parameter, $\lambda$ : 0 (the solid line), 5 (the dashed line), and 10 (the dashdot line). We set $\pi=0.15 / 12$ per month, $\delta=0$, and let $i_{j} / k_{j 0}$ vary from $0.15 / 12$ to $0.20 / 12$ per month.

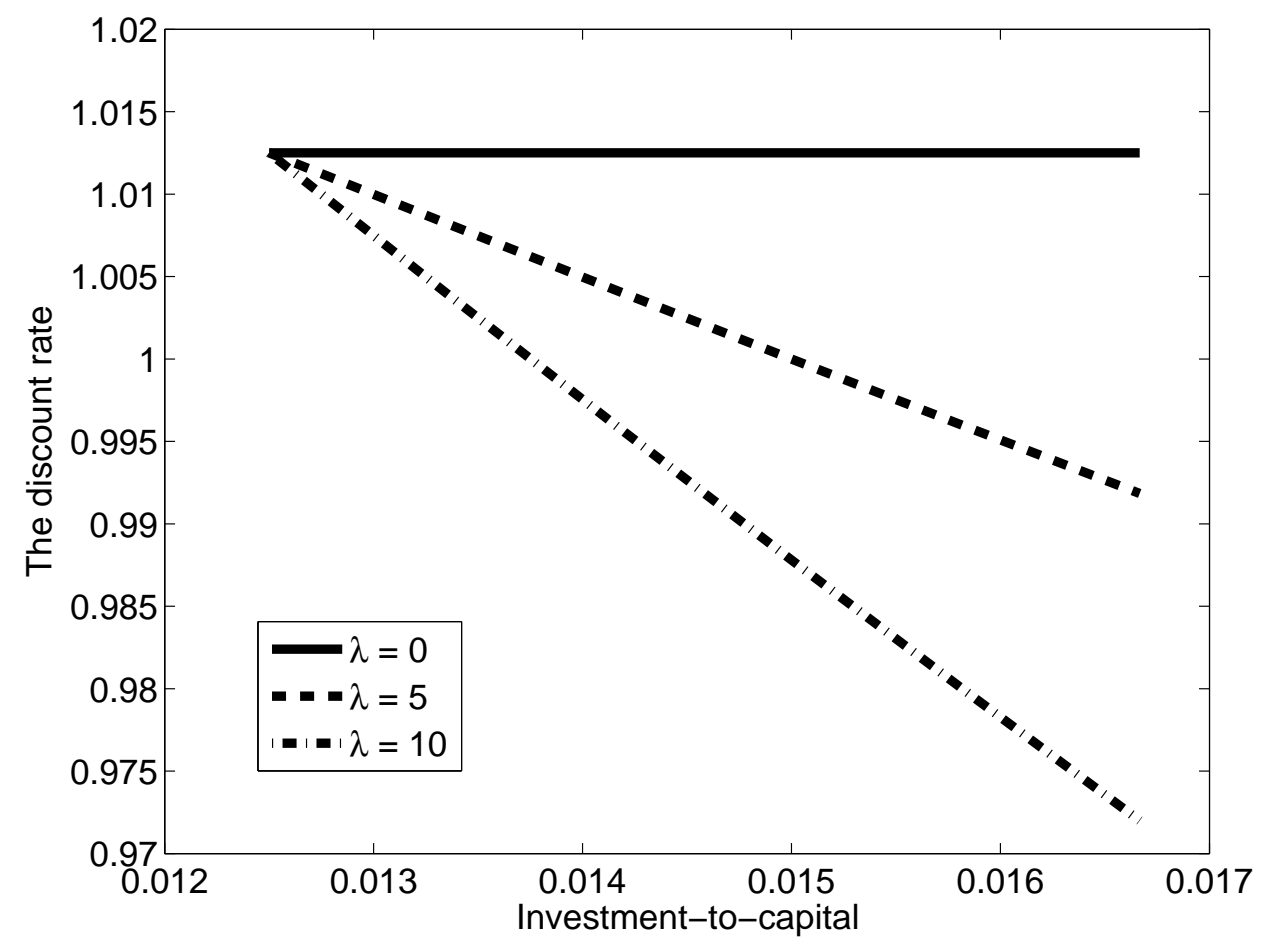

The economic intuition is fairly simple. The partial derivative $\partial r_{j} / \partial i_{j}$ is the inverse of the elasticity of investment with respect to changes in the discount rate. When investment is frictionless $(\lambda=0)$, investment is infinitely elastic to changes in the discount rate, meaning that $r_{j}$ is flat in $i_{j} / k_{j 0}$. With financial frictions $(\lambda>0)$, investment entails financing costs, and higher investment intensity entails higher financing costs. As a result, investment is no longer infinitely elastic to changes in the discount rate. And the magnitude of this elasticity decreases with the financing cost parameter, $\lambda$. The higher $\lambda$ is, the more inelastic investment will be with respect to changes in the discount rate. Equivalently, the higher $\lambda$ is, a given magnitude of change in investment will corre- 
spond to a higher magnitude of change in the discount rate, meaning that investment-to-capital is a more powerful predictor of future returns.

\subsection{Testable Hypotheses}

Based on the model's central prediction, we develop several testable hypotheses. A direct test of the prediction is to check the magnitude of the investment effect in cross-sectional returns across subsamples split by measures of financial constraints. We use three measures of financial constraints including payout ratio, bond ratings, and the Whited-Wu $(2006, W W$ ) index (see Section 3.1 for detailed variable definitions). Firms with low payout ratios, unrated public debt, and high $W W$-index values are more financially constrained, and firms with high payout ratios, rated public debt, and low $W W$-index values are less financially constrained.

We connect the investment effect in theory with three well-known anomalies in empirical capital markets research: the asset growth anomaly, the external finance anomaly, and the accrual anomaly. We view asset growth as the most comprehensive measure of investment intensity, in which investment is simply the change in total assets, including both long-term capital as well as short-term working capital. The external finance effect also is connected to investment. The balance-sheet constraint of firms says that the uses of funds must equal to the sources of funds, meaning that high investment firms must go to external capital markets more often than low investment firms. Lyandres, Sun, and Zhang (2008) show that firms conducting initial public offerings, seasoned equity offerings, and convertible bond offerings invest much more than otherwise similar firms, and that adding an investment factor into standard factor models substantially reduces the magnitude of their long-term underperformance measured as the intercepts from time series regressions. Interpreting accruals as working capital investment, we also view the accrual anomaly as reflecting the general investment effect. Stickney, Brown, and Wahlen (2003) argue that accruals represent a direct form of investment and are an integral part of business growth of firms. Zhang (2007) documents that accruals covary positively with employee growth, external financing, and other aspects of corporate growth. 
In summary, we motivate from the model's theoretical prediction the following testable hypothesis, which we in turn try to refute in the subsequent empirical analysis:

Hypothesis 1. The magnitudes of the asset growth, external finance, and accrual effects should be higher in more constrained firms than in less constrained firms.

We also try to distinguish this financial constraints hypothesis from alternative hypotheses. It is well-known that financial constraints and financial distress are distinct, but related, concepts. Financial constraints are frictions that prevent firms from financing all of their desired investments. This funding inability can be due to credit constraints, inability to issue equity, excessive dependence on bank loans, or illiquidity of assets. In contrast, Wruck (1990) defines financial distress as situations when cash flow is insufficient to cover current obligations. These obligations can include unpaid debt to suppliers and employees as well as missed principal or interest payments to bond holders.

Although conceptually different, disentangling financial constraints from financial distress empirically is much more difficult. Because measures of financial constraints and distress are correlated, it is conceivable that the effect of financial constraints is simply driven by financial distress. And financial distress is beyond the scope of our simple theoretical model. As such, we try to distinguish the effect of financial constraints from that of financial distress, using Ohlson's (1980) $O$-score and Campbell, Hilscher, and Szilagyi's (2008) failure probability as measures of financial distress.

Hypothesis 2. The effect of financial constraints on the magnitudes of the asset growth, external finance, and accrual anomalies is distinct from the effect of financial distress.

Many studies interpret the asset growth, external finance, and accrual anomalies as due to systematic mispricing (e.g., Ritter (1991), Ikenberry, Lakonishok, and Vermaelen (1995), Loughran and Ritter (1995), Sloan (1996), Richardson, Sloan, Soliman, and Tuna (2005), and Cooper, Gulen, and Schill (2008)). If anomalies are driven by mispricing, why do professional arbitrageurs not exploit the trading opportunities and quickly eliminate the mispricing? Shleifer and Vishny (1997) 
argue that, because of a variety of trading frictions, arbitrage is costly and thereby limited. When the costs of arbitrage outweigh the benefits of arbitrage, the systematic mispricing would not be quickly and entirely traded away. This hypothesis stresses the role of trading frictions from the investor side, while our financial constraints hypothesis stresses the role of investment frictions from the firm side. Because they ride on different frictions that probably coexist in the data, the two hypotheses are not mutually exclusive. It is still interesting, however, to study whether the financial constraints effect subsists after controlling for standard limits to arbitrage proxies.

Hypothesis 3. The effect of financial constraints on the magnitudes of the asset growth, external finance, and accrual anomalies is distinct from the effect of limits to arbitrage.

Following Ali, Hwang, and Trombley (2003), we use two measures of limits to arbitrage: dollar trading volume and idiosyncratic stock volatility. The idea behind dollar trading volume is transaction costs. When stocks are mispriced, transaction costs limit the extent to which arbitrageurs can exploit the trading opportunities to eliminate the mispricing. Dollar trading volume is an important indicator of transaction costs in the form of adverse price effects of a trade and the delay in processing the trade. If stocks are heavily traded, trades are more likely to be completed quickly and are less likely to have adverse price impact. If stocks are thinly traded, trades are less likely to be completed quickly and are more likely to have adverse price impact. The idea behind idiosyncratic volatility is that, almost by definition, arbitrage strategies are not diversified. The under-diversification means that arbitrageurs must take idiosyncratic volatility without being compensated with higher expected returns. As such, high idiosyncratic volatility means arbitrage is more costly and limited, and low idiosyncratic volatility means arbitrage is less costly and limited.

\section{Data}

We obtain financial statement data, such as capital expenditure, cash flow, and debt from Compustat and stock returns data from the Center for Research in Security Prices (CRSP). All domestic 
common shares trading on NYSE, AMEX, and NASDAQ with accounting and returns data available are included except for financial firms (firms with four-digit SIC codes between 6000 and 6999). Following Fama and French (1993), we also exclude closed-end funds, trusts, ADRs, REITS, and units of beneficial interest. To mitigate backfilling biases, we require firms to be listed on Compustat for two years before using them. We use the U.S. one-month Treasury bill rates as the risk-free rate in computing excess returns. To be included in the sample, a firm must have all the variables required to compute the relevant variables. The sample period is from July 1963 to December 2006.

\subsection{Measures of Financial Constraints}

We use three measures of financial constraints in our asset pricing tests.

- Payout ratio. The payout ratio is defined as the ratio of total distributions including dividends for preferred stocks (Compustat annual item 19), dividends for common stocks (item 21), and share repurchases (item 115) divided by operating income before depreciation (item 13). At the end of June of each year $t$, we rank firms based on their payout ratios measured at the end of fiscal year $t-1$. We assign those firms in the bottom tercile of the annual payout ratio distribution to the more financially constrained subsample and those firms in the top tercile to the less financially constrained subsample. The payout ratio is a traditional measure of financial constraints (e.g., Fazzari, Hubbard, and Peterson (1988), Almeida, Campello, and Weisbach (2004), and Almeida and Campello (2007)).

- Bond rating. Following Almeida, Campello, and Weisbach (2004) and Almeida and Campello (2007), we retrieve data on firms' bond ratings assigned by Standard \& Poor's and categorize those firms that never had their public debt rated during our sample period as financially constrained. Observations from those firms are only assigned to the constrained subsample in years when the firms report positive debt. The financially unconstrained subsample contains those firms whose bonds have been rated during the sample period. This approach has been used extensively in the corporate finance literature (e.g., Whited (1992), Kashyap, Lamont, 
and Stein (1994), and Cummins, Hasset, and Oliner (1999)).

- The $W W$ index. Following Whited and $\mathrm{Wu}$ (2006), we compute the $W W$ index using Compustat quarterly data as follows:

$W W=-0.091 C F-0.062$ DIV POS +0.021 TLTD $-0.044 L N T A+0.102 I S G-0.035 S G$

in which $C F$ is the ratio of cash flow to total assets, DIVPOS is an indicator that takes the value of one if the firm pays cash dividends, TLTD is the ratio of the long-term debt to total assets, $L N T A$ is the natural $\log$ of total assets, $I S G$ is the firm's three-digit industry sales growth, and $S G$ is firm sales growth. All variables are deflated by the replacement cost of total assets as the sum of the replacement value of the capital stock plus the rest of the total assets. We follow Whited (1992) in computing the replacement value of the capital stock. Because of data limitations of the quarterly long-term debt (Compustat quarterly item 51), the sample period for the $W W$-related tests is from July 1976 to December 2006.

The measures of financial constraints are correlated. At the end of each year in the sample, we calculate all the pairwise cross-sectional Spearman's correlations and report the time series averages. The correlations are -0.21 between payout ratio and bond rating, -0.52 between the $W W$ index and payout ratio, and 0.39 between the $W W$ index and bond rating. All the correlations are significant at the $1 \%$ level (evaluated with time series standard errors).

We also have experimented with the Kaplan and Zingales $(1997, K Z)$ index. We find that the $K Z$ index is only weakly correlated with the other measures, consistent with recent studies that cast doubt on the $K Z$ index as a valid measure of financial constraints (e.g., Almeida, Campello, and Weisbach (2004), Whited and Wu (2006), Hennessy and Whited (2007), and Hadlock and Pierce (2008)). Hadlock and Pierce reestimate Kaplan and Zingales's (1997) ordered logit model on a larger, most recent sample, and find that only two out of five components in the $K Z$ index have signs consistent with the index. As such, we do not use the $K Z$ index to measure financial constraints. 
The corporate finance literature has traditionally used asset size (book value of total assets) to measure financial constraints (e.g., Gilchrist and Himmelberg (1995), Erickson and Whited (2000), and Almeida and Campello (2007)). The cross-sectional Spearman's correlation between asset size and the $W W$ index is -0.94 in our sample. The test results with asset size as a measure of financial constraints are largely similar to those with the $W W$ index (not reported).

\subsection{Portfolios Formed on Anomaly Variables}

We first report the descriptive statistics of one-way sorted portfolios formed on anomaly variables. Following Cooper, Gulen, and Schill (2008), we measure asset growth, denoted AG, as the change in total assets divided by lagged total assets (Compustat annual item 6). We measure net stock issues, denoted NS, as the natural log of the ratio of the split-adjusted shares outstanding at the fiscal yearend in $t-1$ divided by the split-adjusted shares outstanding at the fiscal yearend in $t-2$ (e.g., Fama and French (2008)). We calculate the split-adjusted shares outstanding as Compustat shares outstanding (item 25) times Compustat adjustment factor (item 27). Following Sloan (1996), we measure accruals, denoted AC, as changes in non-cash working capital minus depreciation expense (scaled by average total assets in the recent two years): $(\triangle C A-\triangle C A S H)-(\triangle C L-\triangle S T D-$ $\triangle T P)-D E P$, in which $\triangle C A$ is the change in current assets (item 4), $\triangle C A S H$ is the change in cash or cash equivalents (item 1), $\triangle C L$ is the change in current liabilities (item 5), $\triangle S T D$ is the change in debt included in current liabilities (item 34), $\triangle T P$ is the change in income taxes payable (item 71), and $D E P$ is depreciation and amortization expense (item 14).

At the end of June of each year $t$, we sort stocks into five equal-numbered quintiles on AG, NS, and AC. Portfolio returns are calculated from July of year $t$ to June of year $t+1$, and the portfolios are rebalanced in each June. Table 1 reports average returns in excess of the one-month Treasury bill rates, the CAPM alphas, and the alphas from the Fama-French (1993) three-factor model for all the portfolios. Both equal-weighted and value-weighted results are reported.

Firms with high asset growth earn lower average returns than firms with low asset growth, 
consistent with Cooper, Gulen, and Schill (2008). The high-minus-low AG portfolio earns an equal-weighted average return of $-1.12 \%$ per month $(t=-8.60)$ and a CAPM alpha of $-1.20 \%$ $(t=-9.70)$. The value-weighted average return and CAPM alpha are $-0.36 \%(t=-2.43)$ and $-0.48 \%$ per month $(t=-3.35)$, respectively. The Fama-French model reduces the value-weighted alpha to $-0.07 \%$ per month, but leaves a significant equal-weighted alpha of $-1.01 \%(t=-8.16)$ unexplained. High NS stocks earn lower average returns than low NS stocks. The high-minus-low quintile earns an equal-weighted average return of $-0.70 \%$ per month $(t=-4.99)$ and a CAPM alpha of $-0.86 \%(t=-6.86)$. The value-weighted average returns and alphas for the high-minus-low NS portfolio are largely similar in magnitude to their equal-weighted counterparts. The FamaFrench model cannot explain the net issues puzzle: The equal-weighted alpha is $-0.62 \%$ per month $(t=-5.78)$ and the value-weighted alpha is $-0.44 \%(t=-4.13)$. Firms with high accruals earn lower average returns than firms with low accruals, consistent with Sloan (1996). The high-minus-low $\mathrm{AC}$ quintile has an average equal-weighted return of $-0.57 \%$ per month $(t=-6.95)$ and an average value-weighted return of $-0.25 \%(t=-1.85)$. The Fama-French model produces an equal-weighted alpha of $-0.56 \%$ per month $(t=-6.88)$ and a value-weighted alpha of $-0.28 \%(t=-2.10)$.

\section{Main Empirical Results}

We organize this section around the three testable hypotheses developed in Section 2. Section 4.1 documents the impact of financial constraints on the anomalies in question. Section 4.2 distinguishes the effect of financial constraints from that of financial distress. And Section 4.3 disentangles the effect of financial constraints from that of limits of arbitrage.

\subsection{Do Financial Constraints Affect Capital Markets Anomalies?}

We ask how the magnitudes of the asset growth, net stock issues, and accrual anomalies vary with the degree of financial constraints. Our test design is simple. At the end of June of year $t$, we split the sample into subsamples based on a given measure of financial constraints at the end of fiscal year 
$t-1$. Within each subsample, we sort stocks into five portfolios based on a given anomaly variable. We then compare the magnitude of the average returns and alphas of the high-minus-low portfolios across extreme subsamples. This sample-splitting method based on a priori measures of financial constraints has been used extensively in the corporate finance literature to study the impact of these constraints on firm value and capital investment (e.g., Fazzari, Hubbard, and Peterson (1988)).

\section{The Asset Growth Portfolios}

Table 2 reports the variation of the asset growth effect across subsamples split by financial constraints measures. From Panel A, the equal-weighted average return, CAPM alpha, and FamaFrench alpha of the high-minus-low AG portfolio are $-1.60 \%,-1.68 \%$, and $-1.40 \%$ per month in the low payout ratio (most constrained) tercile, respectively, and are all more than 7.5 standard errors from zero. In contrast, their counterparts in the high payout ratio (least constrained) tercile are $-0.51 \%,-0.55 \%$, and $-0.38 \%$ per month, which are less than one-third of their respective magnitudes. Similarly, the value-weighted average return, CAPM alpha, and Fama-French alpha of the high-minus-low AG portfolio are higher in magnitude in the low payout ratio subsample than in the high payout ratio subsample: $-0.81 \%$ vs. $-0.23 \%,-0.86 \%$ vs. $-0.31 \%$, and $-0.40 \%$ vs. $0.07 \%$ per month, respectively. We also report the $t$-statistics that test the difference in the average return, the CAPM alpha, or the Fama-French alpha of the high-minus-low AG portfolio across the extreme payout ratio subsamples equals zero. The equal-weighted differences are all more than 5.5 standard errors from zero. However, the value-weighted differences are insignificant.

The asset growth effect is stronger in the constrained firms than in the unconstrained firms, as defined by bond ratings. Panel B shows that, in the unconstrained subsample, the equal-weighted average return, CAPM alpha, and Fama-French alpha of the high-minus-low AG portfolio are $-0.71 \%,-0.82 \%$, and $-0.57 \%$ per month, which are lower in magnitude than their counterparts in the constrained subsample, $-1.50 \%,-1.56 \%$, and $-1.43 \%$ per month, respectively. And the differences are all more than 6.9 standard errors from zero. The value-weighted results are similar. The 
value-weighted average return, CAPM alpha, and Fama-French alpha in the unconstrained sample are $-0.32 \%,-0.45 \%$, and $-0.03 \%$ per month, which are smaller in magnitude than their counterparts in the constrained sample, $-0.72 \%,-0.79 \%$, and $-0.47 \%$, respectively. And the differences across the two subsamples are all more than 2.4 standard errors from zero.

The asset growth anomaly is stronger in firms with high $W W$ index values. But this result is only reliable in equal-weighted returns. From Panel C, the equal-weighted average return, CAPM alpha, and Fama-French alpha of the high-minus-low AG portfolio are $-0.49 \%,-0.63 \%$, and $-0.31 \%$ per month, respectively, in the low $W W$ tercile. These estimates are much lower in magnitude than those in the high $W W$ tercile, $-1.66 \%,-1.66 \%$, and $-1.58 \%$ per month. And the differences are more than 3.9 standard errors from zero. However, the differences in value-weighted estimates, ranging from -0.06 to -0.42 , are insignificant.

We also have measured investment as the annual change in property, plant, and equipment plus the annual change in inventories divided by lagged total assets, as in Lyandres, Sun, and Zhang (2008). This variable is arguably a more direct measure of investment. The results are largely similar with the asset growth results in Table 2 (see Appendix A.1 and Table A1 for details).

\section{The Net Stock Issues Portfolios}

Table 3 shows the net stock issues anomaly varies across subsamples split by financial constraints. From Panel A, the equal-weighted average return, CAPM alpha, and Fama-French alpha of the highminus-low NS portfolio are larger in magnitude in the low payout tercile than in the high payout tercile: $-1.08 \%$ vs. $-0.63 \%,-1.24 \%$ vs. $-0.64 \%$, and $-0.96 \%$ vs. $-0.52 \%$ per month, respectively. The differences are all significant at the $5 \%$ level. The value-weighted average return of the high-minuslow NS portfolio is $-0.75 \%$ per month in the low payout subsample, which is higher in magnitude than that in the high payout subsample, $-0.51 \%$. But the difference of $-0.24 \%$ is only marginally significant $(t=-1.78)$. The CAPM alpha also is higher in the more constrained subsample than that in the less constrained subsample: $-0.90 \%$ vs. $-0.50 \%$ per month, and the difference is 2.6 
standard errors from zero. But the Fama-French alphas are similar across the extreme subsamples.

Panel B shows that, in the unconstrained subsample with bond ratings, the equal-weighted average return, CAPM alpha, and Fama-French alpha of the high-minus-low NS portfolio are $-0.49 \%,-0.62 \%$, and $-0.41 \%$ per month, which are lower in magnitude than their counterparts in the constrained subsample without bond ratings, $-0.83 \%,-1.01 \%$, and $-0.77 \%$, respectively. The differences across the two subsamples are more than 2.7 standard errors from zero. The differences in the value-weighted average return, CAPM alpha, and Fama-French alpha are $-0.60 \%,-0.75 \%$, and $-0.50 \%$ per month, which are all more than 3.6 standard errors from zero.

Using the $W W$ index, Panel $\mathrm{C}$ shows that the NS effect is stronger in more financially constrained firms. The equal-weighted average return, CAPM alpha, and Fama-French alpha of the high-minus-low NS portfolio are $-0.45 \%,-0.62 \%$, and $-0.45 \%$ per month in the low $W W$ tercile, which are more than halved in magnitude from their counterparts, $-1.09 \%,-1.34 \%$, and $-1.13 \%$, respectively, in the high $W W$ tercile. And the differences across the two subsamples are all more than 2.5 standard errors from zero. The value-weighted results are similar: The differences in average return, CAPM alpha, and Fama-French alpha are $-0.86 \%,-0.97 \%$, and $-0.85 \%$ per month, which are all more than 3.6 standard errors from zero.

\section{The Accrual Portfolios}

Table 4 shows that the accrual anomaly also is stronger in more constrained firms, although the effect exists mostly in equal-weighted returns. From Panel A, the equal-weighted average return, CAPM alpha, and Fama-French alpha of the high-minus-low AC portfolio are $-0.79 \%,-0.82 \%$, and $-0.75 \%$ per month in the low payout subsample, respectively. In contrast, their magnitudes are more than halved in the high payout subsample: $-0.34 \%,-0.37 \%$, and $-0.35 \%$ per month, respectively. And the differences are more than 2.9 standard errors from zero. The value-weighted average return, CAPM alpha, and Fama-French alpha of the high-minus-low AC portfolio also are higher in magnitude in the more constrained subsample: $-0.47 \%$ vs. $-0.15 \%,-0.49 \%$ vs. $-0.19 \%$, and 
$-0.46 \%$ vs. $-0.23 \%$ per month, respectively. However, the differences are all within 1.4 standard errors of zero. From Panel B, splitting the sample by bond rating yields largely similar results.

From Panel C, splitting the sample by the $W W$ index also yields significant results in equalweighted returns, but not in value-weighted returns. In the low $W W$ subsample, the equa-weighted average return, CAPM alpha, and Fama-French alpha are $-0.26 \%,-0.27 \%$, and $-0.25 \%$ per month, which are more than halved in magnitude from their counterparts in the the high $W W$ subsample, $-0.77 \%,-0.75 \%$, and $-0.67 \%$ per month, respectively. The differences across the two subsamples are all more than 2.5 standard errors from zero. However, the value-weighted average return, CAPM alpha, and Fama-French alpha in the low $W W$ tercile are actually higher in magnitude than their counterparts in the high $W W$ tercile, but the differences are close to zero.

We also have used net operating assets from Hirshleifer, Hou, Teoh, and Zhang (2004) as an alternative measure of accruals. Following Hirshleifer et al., we measure net operating assets as operating assets minus operating liabilities scaled by lagged total assets. This variable is closely related to the comprehensive measure of accruals advocated by Richardson, Sloan, Soliman, and Tuna (2005). The impact of financial constraints on the net operating assets effect is largely similar to the impact on the asset growth effect (see Appendix A.1 and Table A2 for details).

\subsection{Disentangling Financial Constraints from Financial Distress}

This subsection tests Hypothesis 2 that the effect of financial constraints is distinct from that of distress on the anomalies. We measure financial distress with Ohlson's (1980) O-score, defined as:

$O=-1.32-0.407 \log ($ Total assets $)+6.03\left(\frac{\text { Total liabilities }}{\text { Total assets }}\right)-1.43\left(\frac{\text { Working capital }}{\text { Total assets }}\right)$

$+0.076\left(\frac{\text { Current liabilities }}{\text { Current assets }}\right)-1.72(1$ if total liabilities $>$ total assets, 0 if otherwise $)$

$-2.37\left(\frac{\text { Net income }}{\text { Total assets }}\right)-1.83\left(\frac{\text { Funds from operations }}{\text { Total liabilities }}\right)$

+0.285 (1 if a net loss for the last two years, 0 otherwise $)-0.521\left(\frac{\text { Net }_{\text {income }}-\text { Net income }_{t-1}}{\mid \text { Net income }_{t}|+| \text { Net income }_{t-1} \mid}\right)$ 
in which total assets are measured as Compustat annual item 6, total liabilities as item 181, working capital as current assets (item 4) minus current liabilities (item 5), net income as item 172, and funds from operations as item 13. The correlations of $O$-score with measures of financial constraints are -0.37 with payout ratio, 0.21 with bond ratings, and 0.38 with the $W W$ index. As such, it is necessary to disentangle the effect of financial constraints from the effect of financial distress.

Table 5 shows how the asset growth, net stock issues, and accrual anomalies vary across subsamples split by $O$-score. The test design is the same as in Table 2 . At the end of June of year $t$, we split the sample into three equal-numbered subsamples by $O$-score in fiscal year ending in calendar year $t-1$. Within each subsample, we sort stocks into five quintile portfolios based on a given anomaly variable, and compare the magnitudes of the average returns and alphas of the high-minus-low portfolios across different $O$-score subsamples. The table shows that the equal-weighted asset growth and net stock issues effects are stronger in more distressed firms than in less distressed firms. The value-weighted results go in the same direction, but are insignificant. And for the most part, the magnitude of the accrual effect does not vary significantly across the extreme $O$-score subsamples.

\section{The Horse Race: Financial Constraints versus Financial Distress}

To distinguish the effect of financial constraints from the effect of financial distress, we study the variation in the magnitude of the anomalies across subsamples split jointly by a given measure of financial constraints and a given measure of financial distress. The test design is a natural extension of that in Tables 2 to 5 . At the end of June of year $t$, we first split the sample into six subsamples by an independent three-by-two sort on payout ratio (or the $W W$ index) and $O$-score. We also split the sample into four subsamples by an independent two-by-two sort on bond ratings and $O$-score. The sort on bond ratings categorizes firms into those with debt outstanding but without a bond rating and those with bond ratings. All the sorting variables are measured in fiscal year ending in calendar year $t-1$. Within each subsample, firms are sorted into five equal-numbered portfolios on a given anomaly variable. Portfolio returns are computed from July of year $t$ to June of year $t+1$, 
and the portfolios are rebalanced at the end of each June.

Table 6 reports the results. We only report the results for the high-minus-low portfolios to save space. Panel A shows the horse race between payout ratio and $O$-score. Payout ratio dominates the $O$-score in driving the magnitude of the anomalies. The differences in the equal-weighted average return, CAPM alpha, and Fama-French alpha of the high-minus-low AG portfolio across the high and low payout ratio subsamples are $-0.69 \%,-0.85 \%$, and $-0.64 \%$ per month, which are all significant at the $5 \%$ level, in the low $O$-score universe. The corresponding differences in the high $O$-score universe are largely similar: $-0.87 \%,-0.88 \%$, and $-0.80 \%$, respectively. For comparison, the differences in the equal-weighted average return, CAPM alpha, and Fama-French alpha of the high-minus-low AG portfolio across the high and low $O$-score subsamples are $-0.50 \%,-0.29 \%$, and $-0.52 \%$ per month in the low payout ratio subsample, and are $-0.32 \%,-0.26 \%$, and $-0.36 \%$, respectively, in the high payout ratio subsample. Although mostly significant at the $5 \%$ level, the differences generated from splitting the sample on $O$-scores are often much lower in magnitude than the differences from splitting on the payout ratio.

From Panel A, payout ratio also dominates $O$-score in driving the net stock issues and accrual anomalies. The differences in the equal-weighted average return, CAPM alpha, and Fama-French alpha of the high-minus-low NS portfolio across the high and low payout ratio subsamples in the high $O$-score universe are $-0.46 \%,-0.65 \%$, and $-0.53 \%$ per monthly, which are all significant at the $5 \%$ level. In contrast, the corresponding differences across the high and low $O$-score subsamples in the low payout ratio universe are $-0.25 \%,-0.22 \%$, and $-0.27 \%$, respectively, none of which are significant. The differences in the equal-weighted average return, CAPM alpha, and Fama-French alpha of the high-minus-low accrual portfolio across the high and low payout ratio subsamples in the low $O$-score universe are $-0.39 \%,-0.43 \%$, and $-0.40 \%$ per month, which are all significant at the $5 \%$ level. In contrast, the corresponding differences across the high and low $O$-score subsamples in the low payout ratio universe are $-0.22 \%,-0.11 \%$, and $-0.17 \%$, none of which are significant. 
Panel B shows that bond rating also dominates $O$-score in driving the anomalies. The differences in the value-weighted average return, CAPM alpha, and Fama-French alpha of the high-minus-low AG portfolio across the constrained and unconstrained subsamples in the low $O$-score universe are $-0.37 \%,-0.39 \%$, and $-0.41 \%$, respectively, all of which are significant at the $5 \%$ level. In contrast, the corresponding differences across the high and low $O$-score subsamples in the unconstrained universe are $-0.05 \%, 0.09 \%$, and $-0.29 \%$, none of which are significant. However, the effects of constraints and distress on equal-weighted returns are more comparable in magnitude.

Panel B also demonstrates the complete dominance of bond rating over $O$-score in driving the net stock issues effect. The impact of bond rating on the anomaly's magnitude is economically large and statistically significant even after we control for $O$-score, but controlling for bond rating eliminates the impact of $O$-score. In particular, the differences in the value-weighted average return, CAPM alpha, and Fama-French alpha of the high-minus-low NS portfolio across the constrained and unconstrained subsamples in the low $O$-score universe are $-0.63 \%,-0.79 \%$, and $-0.63 \%$, respectively, all of which are significant at the $5 \%$ level. In contrast, the corresponding differences across the high and low $O$-score subsamples in the unconstrained universe are $-0.09 \%,-0.08 \%$, and $-0.11 \%$, none of which are significant. Bonding rating also dominates $O$-score in driving the accrual anomaly, but the results are less dramatic than those for the net stock issues anomaly.

Panel $\mathrm{C}$ shows that the $W W$ index completely dominates $O$-score in driving the net stock issues anomaly, and to a lesser extent, in driving the asset growth and accrual anomalies. The differences in the equal-weighted average return, CAPM alpha, and Fama-French alpha of the high-minus-low AG portfolio across the high and low $W W$ subsamples in the low $O$-score universe are $-0.75 \%,-0.77 \%$, and $-1.05 \%$ per month, respectively. In contrast, the corresponding differences across the high and low $O$-score subsamples in the low $W W$ universe are $-0.30 \%,-0.17 \%$, and $-0.37 \%$. The differences in the value-weighted average return, CAPM alpha, and Fama-French alpha of the high-minus-low NS portfolio across the extreme $W W$ subsamples in the low $O$-score universe are $-0.77 \%,-0.90 \%$, and $-0.94 \%$, respectively, all of which are significant at the $5 \%$ level. 
In contrast, the corresponding differences across the extreme distress subsamples in the low $W W$ universe are $-0.23 \%,-0.23 \%$, and $-0.17 \%$, none of which are significant. The differences in the equal-weighted average return, CAPM alpha, and Fama-French alpha of the high-minus-low accrual portfolio across the extreme $W W$ subsamples in the high $O$-score universe are $-0.52 \%,-0.55 \%$, and $-0.44 \%$. In contrast, the corresponding differences across the extreme $O$-score subsamples in the high $W W$ universe are only $-0.24 \%,-0.07 \%$, and $-0.07 \%$, respectively.

\section{Robustness}

We evaluate the robustness of the results using an alternative measure of financial distress, which is the failure probability provided by Campbell, Hilscher, and Szilagyi (2008). Although specific details vary, we continue to observe that the effect of financial distress does not subsume, and is often subsumed by, the effect of financial constraints (see Appendix A.2 and Tables A3 and A4 for details).

\subsection{Disentangling Financial Constraints from Limits to Arbitrage}

Although variables that are proxies for limits to arbitrage affect capital markets anomalies, their effect does not subsume, and is often subsumed by, the effect of financial constraints.

\section{The Impact of Limits to Arbitrage}

Following Ali, Hwang, and Trombley (2003), we use two measures of limits to arbitrage: dollar trading volume and idiosyncratic volatility. Dollar trading volume is the annual volume of trade in a firm's shares from July 1 of year $t-1$ to June 30 of year $t$, in millions of dollars. At the end of each June, we compute dollar volume for each firm as the sum of last twelve months' daily dollar volume, which is the product of share volume and daily closing price from CRSP. Arbitrages are more limited for stocks with low trading volume (indicating low liquidity and high transaction costs) than for stocks with high trading volume (indicating high liquidity and low transaction costs). We obtain idiosyncratic volatility by regressing daily stock returns on a value-weighted market portfolio over a maximum of 250 days ending on June 30 of year $t$ and then calculating the volatility of the 
residuals. Arbitrages are more limited for stocks with higher idiosyncratic volatility.

The limits to arbitrage proxies are correlated with financial constraints measures. At the end of each year we calculate the pairwise cross-sectional Spearman's correlations and report the time series averages. The correlations of trading volume with constraints measures are 0.28 with payout ratio, -0.38 with bond rating, and -0.75 with the $W W$ index, and the correlations of idiosyncratic volatility are -0.54 with payout ratio, 0.27 with bond rating, and 0.65 with the $W W$ index. All the correlations are significant at the $5 \%$ level. As such, it is necessary to disentangle the effect of financial constraints from that of limits to arbitrage.

Table 7 shows how the anomalies vary across subsamples split by trading volume. The test design is the same as in Table 2. At the end of each June of year $t$, we split the sample into three equal-numbered subsamples by trading volume in June of year $t$. Within each subsample, we sort stocks into five portfolios based on a given anomaly variable, and compare the magnitude of the anomaly across different subsamples. The table shows some evidence that the equal-weighted asset growth effect is stronger in the low volume tercile than in the high volume tercile, but the effect is nonexistent in value-weighted returns. The equal-weighted net stock issues effect is actually stronger in the high volume stocks than in the low volume stocks. And the differences in the magnitude of the accrual effect across the extreme trading volume subsamples are all within 1.8 standard errors from zero. In all, the evidence on the limits to arbitrage hypothesis is mixed when we use dollar volume as a proxy for the arbitrage limits.

Table 8 shows how the anomalies vary across subsamples split by idiosyncratic volatility. At the end of each June of year $t$, we split the sample into three equal-numbered subsamples by idiosyncratic volatility measured with daily returns ending on June 30 of year $t$. Within each subsample, we sort stocks into five portfolios based on a given anomaly variable, and compare the magnitude of the anomaly across different subsamples. The table shows strong impact of idiosyncratic volatility. The differences in equal-weighted average return, CAPM alpha, and Fama-French alpha of the 
high-minus-low AG portfolio across the high and low idiosyncratic volatility subsamples are around $-1.50 \%$ per month, and are all more than eight standard errors from zero. The value-weighted differences range from $-0.89 \%$ to $-1.08 \%$ per month, and are more than 3.5 standard errors from zero. The equal-weighted differences of the high-minus-low NS portfolio are around $-0.50 \%$ per month, and are more than three standard errors from zero. The value-weighted differences are largely similar. Finally, the equal-weighted differences of the high-minus-low accrual portfolio are economically large and statistically significant, but the value-weighted differences are not.

\section{The Horse Race: Financial Constraints versus Limits to Arbitrage}

To disentangle the effect of financial constraints from the effect of limits to arbitrage, we examine how anomalies vary in the magnitude across subsamples split jointly by a constraints measure and by a proxy for limits to arbitrage. The test design is the similar to Table 6 . At the end of June of year $t$, we split the sample with an independent three-by-two sort on payout ratio (or the $W W$ index) and trading volume (or idiosyncratic volatility). We also split the sample into four samples by an independent two-by-two sort on bond rating and trading volume (or idiosyncratic volatility). The constraints proxies are measured in the fiscal yearend of $t-1$, but the limits to arbitrage proxies are measured in June of year $t$. Within each subsample, we sort stocks into five equal-numbered portfolios on a given anomaly variable, and calculate returns from July of year $t$ to June of year $t+1$. Only the results for the high-minus-low portfolios are reported to save space.

Table 9 reports the horse race between financial constraints and trading volume. In general, financial constraints dominate trading volume in driving the anomalies. Without discussing the details, we note that bond rating completely dominates trading volume in driving the AG effect. Payout ratio and bond rating retain some explanatory power for the equal-weighted accrual anomaly after we control for trading volume, but trading volume shows no explanatory power after we control for payout ratio or bond rating. The $W W$ index also shows stronger explanatory power than trading volume in driving the asset growth effect. In particular, Panel $\mathrm{C}$ shows that after we control for 
the $W W$ index, the average return, CAPM alpha, and Fama-French alpha of zero-cost AG, NS, and $\mathrm{AC}$ portfolios in the low volume subsample are mostly lower in magnitude than their counterparts in the high volume subsample. This evidence casts doubt on the limits to arbitrage hypothesis.

Table 10 reports the horse race between financial constraints and idiosyncratic volatility. We note that idiosyncratic volatility dominates the constraints measures in driving the asset growth and net stock issues effects, but the constraints retain some explanatory power even after we control for idiosyncratic volatility. In particular, the equal-weighted differences in the average return, CAPM alpha, and Fama-French alpha across the extreme idiosyncratic volatility subsamples are $-1.13 \%,-1.05 \%$, and $-1.12 \%$ per month, respectively, in the low payout ratio subsample. These estimates are higher in magnitude than the corresponding equal-weighted differences between the low and high payout ratio subsamples in the high idiosyncratic volatility universe: $-0.44 \%,-0.44 \%$, and $-0.37 \%$, respectively. The impact of constraints is more comparable with the impact of idiosyncratic volatility on the accrual anomaly. In particular, the equal-weighted differences in the average return, CAPM alpha, and Fama-French alpha across the extreme payout ratio subsamples in the low idiosyncratic volatility subsample are $-0.53 \%,-0.56 \%$, and $-0.48 \%$ per month, which are higher in magnitude than the corresponding equal-weighted differences between the extreme idiosyncratic volatility subsamples in the high payout ratio universe: $-0.41 \%,-0.42 \%$, and $-0.40 \%$, respectively.

It is worthwhile to note that limits to arbitrage are unlikely to be the only source that drives the strong relation between idiosyncratic volatility and the magnitude of anomalies. Idiosyncratic return volatility is highly correlated with total return volatility in the cross-section (e.g., Ang, Hodrick, Xing, and Zhang (2006)). And mechanically, a sample of firms with more volatile stock returns is likely to contain more cross-sectional dispersion in expected returns at any point of time than a sample of firms with less volatile stock returns. Sagi and Seasholes (2007) use this mechanism to interpret their evidence that momentum profits are stronger in firms with high revenue volatility. In particular, their real options model does not admit any limits of arbitrage. 


\section{Conclusion}

Our central insight is that the magnitude of the asset growth, net stock issues, and accrual anomalies tends to be higher in financially more constrained firms than in financially less constrained firms. In a frictionless world, investment is perfectly elastic to changes in the discount rate. With financial frictions, investment is less elastic, meaning that a given magnitude of change in investment is associated with a higher magnitude of change in the discount rate. Equivalently, investment is a more powerful predictor of future stock returns when financial frictions are more severe. Our empirical tests support this theoretical prediction. Further tests show that this effect of financial constraints is distinct from the effect of financial distress and the effect of limits of arbitrage on the anomalies. 


\section{References}

Ali, Ashiq, Lee-Seok Hwang, and Mark A. Trombley, 2003, Arbitrage risk and the book-to-market anomaly, Journal of Financial Economics 69, 355-373.

Almeida, Heitor and Murillo Campello, 2007, Financial constraints, asset tangibility, and corporate investment, Review of Financial Studies 20 (5), 1429-1460.

Almeida, Heitor, Murillo Campello, and Michael Weisbach, 2004, The cash flow sensitivity of cash, Journal of Finance 59, 1777-1804.

Anderson, Christopher W. and Luis Garcia-Feijóo, 2006, Empirical evidence on capital investment, growth options, and security returns, Journal of Finance 61 (1), 171-194.

Ang, Andrew, Robert J. Hodrick, Yuhang Xing, and Xiaoyan Zhang, 2006, The cross-section of volatility and expected returns, Journal of Finance 61 (1), 259-299.

Campbell, John Y., Jens Hilscher, and Jan Szilagyi, 2008, In search of distress risk, Journal of Finance 63, 2899-2939.

Campello, Murillo and Long Chen, 2005, Are financial constraints priced? Evidence from firm fundamentals, stocks, and bonds, working paper, University of Illinois and Washington University in St. Louis.

Cochrane, John H., 1991, Production-based asset pricing and the link between stock returns and economic fluctuations, Journal of Finance 46, 209-237.

Cochrane, John H., 1996, A cross-sectional test of an investment-based asset pricing model, Journal of Political Economy 104, 572-621.

Cooper, Michael J., Huseyin Gulen, and Michael J. Schill, 2008, Asset growth and the cross-section of stock returns, Journal of Finance 63, 1609-1652.

Cummins, Jason G., Kevin A. Hassett, and Stephen D. Oliner, 1999, Investment behavior, observable expectations, and internal funds, American Economic Review 96 (3), 796-810.

Erickson, Timothy and Toni M. Whited, 2000, Measurement error and the relationship between investment and Q, Journal of Political Economy 108, 1027-1057.

Fama, Eugene F., 1998, Market efficiency, long-term returns, and behavioral finance, Journal of Financial Economics 49, 283-306.

Fama, Eugene F. and Kenneth R. French, 1993, Common risk factors in the returns on stocks and bonds, Journal of Financial Economics 33, 3-56.

Fama, Eugene F. and Kenneth R. French, 2008, Dissecting anomalies, Journal of Finance 63, $1653-1678$.

Fazzari, Steven M., R. Glenn Hubbard, and Bruce C. Peterson, 1988, Financing constraints and corporate investment, Brookings Papers on Economic Activity 1, 141-195.

Garlappi, Lorenzo and Hong Yan, 2007, Financial distress and the cross section of equity returns, working paper, University of Texas and University of South Carolina. 
Gilchrist, Simon and Charles P. Himmelberg, 1995, Evidence on the role of cash flow for investment, Journal of Monetary Economics 36, 541-572.

Hadlock, Charles J., and Joshua R. Pierce, 2008, Does the $K Z$ index provide a useful measure of financial constraints? working paper, Michigan State University.

Hahn, Jaehoon and Hangyong Lee, 2009, Financial constraints, debt capacity, and the cross section of stock returns, Journal of Finance 64, 891-921.

Hennessy, Christopher A., and Toni M. Whited, 2007, How costly is external financing? Evidence from a structural estimation, Journal of Finance 62, 1705-1745.

Hirshleifer, David, Kewei Hou, Siew Hong Teoh, and Yinglei Zhang, 2004, Do investors overvalue firms with bloated balance sheets? Journal of Accounting and Economics 38, 297-331.

Ikenberry, David, Josef Lakonishok, and Theo Vermaelen, 1995, Market underreaction to open market share repurchases, Journal of Financial Economics 39, 181-208.

Kaplan, Steven N. and Luigi Zingales, 1997, Do investment-cash flow sensitivities provide useful measures of financial constraints? Quarterly Journal of Economics 112, 169-215.

Kashyap, Anil K., Owen A. Lamont, and Jeremy C. Stein, 1994, Credit conditions and the cyclical behavior of inventories, Quarterly Journal of Economics 109 (3), 565-592.

Lettau, Martin and Sydney C. Ludvigson, 2002, Time-varying risk premia and the cost of capital: An alternative implication of the $Q$ theory of investment, Journal of Monetary Economics $49,31-66$.

Lintner, John, 1965, The valuation of risk assets and the selection of risky investments in stock portfolios and capital budgets, Review of Economics and Statistics 47, 13-37.

Loughran, Tim and Jay R. Ritter, 1995, The new issues puzzle, Journal of Finance 50, 23-51.

Lyandres, Evgeny, Le Sun, and Lu Zhang, 2008, The new issues puzzle: Testing the investmentbased explanation, Review of Financial Studies 21 (6), 2825-2855.

Ohlson, James A., 1980, Financial ratios and the probabilistic prediction of bankruptcy, Journal of Accounting Research 18 (1), 109-131.

Richardson, Scott A., Richard G. Sloan, Mark T. Soliman, and Irem Tuna, 2005, Accrual reliability, earnings persistence, and stock prices, Journal of Accounting and Economics 39, 437-485.

Ritter, Jay R., 1991, The long-run performance of initial public offerings, Journal of Finance 46, $3-27$.

Sagi, Jacob S. and Mark S. Seasholes, 2007, Firm-specific attributes and the cross-section of momentum, Journal of Financial Economics 84, 389-434.

Sharpe, William F., 1964, Capital asset prices: A theory of market equilibrium under conditions of risk, Journal of Finance 19, 425-442.

Shleifer, Andrei and Robert Vishny, 1997, The limits of arbitrage, Journal of Finance 52, 35-55. 
Sloan, Richard G., 1996, Do stock prices fully reflect information in accruals and cash flows about future earnings? The Accounting Review 71 (3), 289-315.

Spiess, Katherine D. and John Affleck-Graves, 1995, Underperformance in long-run stock returns following seasoned equity offerings, Journal of Financial Economics 38, 243-267.

Stickney, Clyde P., Paul Brown, and James M. Wahlen, 2003, Financial Reporting and Statement Analysis: A Strategic Approach, 5th ed., South-Western College Publishing.

Titman, Sheridan, K. C. John Wei, and Feixue Xie, 2004, Capital investments and stock returns, Journal of Financial and Quantitative Analysis 39, 677-700.

Whited, Toni M., 1992, Debt, liquidity constraints, and corporate investment: Evidence from panel data, Journal of Finance 47, 1425-1460.

Whited, Toni M. and Guojun Wu, 2006, Financial constraints risk, Review of Financial Studies $19(2), 531-559$.

Wruck, Karen H., 1990, Financial distress, reorganization, and organizational efficiency, Journal of Financial Economics 27, 419-444.

Xing, Yuhang, 2008, Interpreting the value effect through the $Q$-theory: An empirical investigation, Review of Financial Studies 21, 1767-1795.

Zhang, X. Frank, 2007, Accruals, investment, and the accrual anomaly, The Accounting Review $82,1333-1363$. 
Table 1 : Descriptive Statistics of One-Way Quintile Portfolios Sorted on Asset Growth, Net Stock Issues, and Accruals in the Full Sample (July 1963-December 2006, 534 Months)

Asset growth (AG) is the change in total assets (Compustat annual item 6) divided by lagged total assets. The net stock issues (NS) are the natural log of the ratio of the split-adjusted shares outstanding at the fiscal year-end in $t-1$ divided by the split-adjusted shares outstanding at the fiscal year-end in $t-2$. The split-adjusted shares outstanding is Compustat shares outstanding (item 25) times the Compustat adjustment factor (item 27). Accruals (AC) are changes in non-cash working capital minus depreciation expense (scaled by average total assets in the recent two years): $(\triangle C A-\triangle C A S H)-(\triangle C L-\triangle S T D-\triangle T P)-D E P$, in which $\triangle C A$ is the change in current assets (item 4), $\triangle C A S H$ is the change in cash or cash equivalents (item 1), $\triangle C L$ is the change in current liabilities (item 5), $\triangle S T D$ is the change in debt included in current liabilities (item 34), $\triangle T P$ is the change in income taxes payable (item 71), and $D E P$ is depreciation and amortization expense (item 14). At the end of each June of year $t$, firms are categorized into five equal-numbered portfolios based on a given sorting variable. Portfolio returns are computed from July of year $t$ to June of year $t+1$, and the portfolios are rebalanced in each June. Excess return $(r)$ is the difference between portfolio returns and one-month Treasury bill rate. The CAPM alphas $(\alpha)$ and Fama-French alphas $\left(\alpha_{F F}\right)$ are the intercepts from regressing portfolio excess returns on the market factor and the Fama-French three factors, respectively. The superscript $e w$ denotes equal-weighted returns and $v w$ denotes value-weighted returns. The $t$-statistics are adjusted for heteroscedasticity and autocorrelations.

\begin{tabular}{|c|c|c|c|c|c|c|c|c|c|c|c|c|c|c|c|c|c|c|}
\hline & \multicolumn{6}{|c|}{ Panel A: Asset growth (AG) } & \multicolumn{6}{|c|}{ Panel B: Net share issues (NS) } & \multicolumn{6}{|c|}{ Panel C: Accruals (AC) } \\
\hline & $r^{e w}$ & $\alpha^{e w}$ & $\alpha_{F F}^{e w}$ & $r^{v w}$ & $\alpha^{v w}$ & $\alpha_{F F}^{v w}$ & $r^{e w}$ & $\alpha^{e w}$ & $\alpha_{F F}^{e w}$ & $r^{v w}$ & $\alpha^{v w}$ & $\alpha_{F F}^{v w}$ & $r^{e w}$ & $\alpha^{e w}$ & $\alpha_{F F}^{e w}$ & $r^{v w}$ & $\alpha^{v w}$ & $\alpha_{F F}^{v w}$ \\
\hline Low & 1.49 & 0.92 & 0.56 & 0.65 & 0.15 & -0.01 & 1.16 & 0.68 & 0.30 & 0.68 & 0.24 & 0.12 & 1.21 & 0.62 & 0.33 & 0.52 & -0.02 & 0.10 \\
\hline 2 & 1.03 & 0.55 & 0.22 & 0.56 & 0.14 & 0.01 & 1.06 & 0.58 & 0.19 & 0.49 & 0.09 & 0.01 & 1.07 & 0.54 & 0.25 & 0.49 & 0.03 & 0.04 \\
\hline 3 & 0.85 & 0.37 & 0.10 & 0.47 & 0.05 & -0.01 & 0.94 & 0.40 & 0.14 & 0.55 & 0.07 & 0.12 & 0.93 & 0.40 & 0.11 & 0.59 & 0.11 & 0.12 \\
\hline 4 & 0.77 & 0.23 & 0.00 & 0.52 & 0.02 & 0.16 & 0.86 & 0.26 & 0.09 & 0.45 & -0.10 & & 0.85 & 0.29 & 0.03 & 0.37 & -0.13 & -0.04 \\
\hline High & 0.37 & -0.29 & -0.45 & 0.29 & -0.33 & -0.09 & 0.46 & -0.17 & -0.31 & 0.14 & -0.40 & -0.32 & 0.63 & 0.01 & -0.24 & 0.27 & -0.35 & -0.18 \\
\hline $\mathrm{H}-\mathrm{L}$ & -1.12 & -1.20 & -1.01 & -0.36 & -0.48 & -0.07 & -0.70 & -0.86 & -0.62 & -0.55 & -0.64 & -0.44 & -0.57 & -0.61 & -0.56 & -0.25 & -0.33 & -0.28 \\
\hline$t_{\mathrm{H}-\mathrm{L}}$ & -8.60 & -9.70 & -8.16 & -2.43 & -3.35 & -0.59 & -4.99 & -6.86 & -5.78 & -4.40 & -5.36 & -4.13 & -6.95 & -7.76 & -6.88 & -1.85 & -2.54 & -2.10 \\
\hline
\end{tabular}


Table 2 : The Asset Growth Effect Across Subsamples Split by Payout Ratio, Bond Rating, and the Whited-Wu (WW) Index

In June of each year $t$, we split the sample into three equal-numbered subsamples by payout ratio (Panel A), two subsamples by bond ratings (Panel B), and three equal-numbered subsamples by the $W W$ index (Panel C), all measured at the end of fiscal year $t-1$. In Panels A and B, the sample is from July 1963 to December 2006 (534 months). In Panel C, the sample is from July 1976 to December 2006 (378 months) because of the quarterly data limitation for long-term debt in the construction of the $W W$ index. Payout ratio is defined as the sum of dividends and stock repurchase divided by operating income. In Panel B, the constrained subsample contains all the firms with debt outstanding but without a bond rating, and the unconstrained subsample contains all the firms whose bonds are rated. See Section 3 for details of constructing the $W W$ index. Within each subsample, we sort firms into five equal-numbered portfolios based on asset growth (AG) defined as the change in total assets (item 6) divided by lagged total assets. The high-minus-low portfolio (H-L AG) is long in the high AG portfolio and short in the low AG portfolio. Portfolio returns are computed from July of year $t$ to June of year $t+1$. The portfolios are rebalanced at the end of each June. Excess return $(r)$ is the difference between portfolio returns and the one-month Treasury bill rate. The CAPM alphas $(\alpha)$ and Fama-French alphas $\left(\alpha_{F F}\right)$ are the intercepts from regressing portfolio excess returns on the market factor and the three Fama-French factors, respectively. The superscript $e w$ denotes equal-weighted returns and $v w$ denotes value-weighted returns. The $t$-statistics, $t_{\mathrm{H}-\mathrm{L}}$, are adjusted for heteroscedasticity and autocorrelations.

\begin{tabular}{|c|c|c|c|c|c|c|c|c|c|c|c|c|c|c|c|c|c|c|}
\hline & \multicolumn{6}{|c|}{ Panel A: Subsamples by payout ratio } & \multicolumn{6}{|c|}{ Panel B: Subsamples by bond rating } & \multicolumn{6}{|c|}{ Panel C: Subsamples by the $W W$ index } \\
\hline & \multicolumn{6}{|c|}{ Low payout ratio (most constrained) } & \multicolumn{6}{|c|}{ With bond rating (unconstrained) } & \multicolumn{6}{|c|}{ Low $W W$ (least constrained) } \\
\hline & $r^{e w}$ & $\alpha^{e w}$ & $\alpha_{F F}^{e w}$ & $r^{v w}$ & $\alpha^{v w}$ & $\alpha_{F F}^{v w}$ & $r^{e w}$ & $\alpha^{e w}$ & $\alpha_{F F}^{e w}$ & $r^{v w}$ & $\alpha^{v w}$ & $\alpha_{F F}^{v w}$ & $r^{e w}$ & $\alpha^{e w}$ & $\alpha_{F F}^{e w}$ & $r^{v w}$ & $\alpha^{v w}$ & $\alpha_{F F}^{v w}$ \\
\hline Low & 1.81 & 1.15 & 0.75 & 0.97 & 0.23 & 0.11 & 1.32 & 0.77 & 0.45 & 0.63 & 0.16 & 0.00 & 0.89 & 0.28 & -0.15 & 0.76 & 0.19 & 0.00 \\
\hline 2 & 1.40 & 0.80 & 0.41 & 0.76 & 0.09 & -0.02 & 0.92 & 0.46 & 0.19 & 0.51 & 0.12 & 0.02 & 0.83 & 0.30 & & .58 & 0.07 & -0.02 \\
\hline 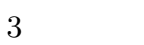 & 1.12 & 0.51 & 0.19 & 0.77 & 0.10 & 0.15 & 0.83 & 0.36 & 0.13 & 0.44 & 0.01 & -0 . & 0.77 & 0.22 & & 0.65 & 0.11 & 0.06 \\
\hline 1 & 0.80 & 0.15 & -0.08 & 0.41 & -0.29 & -0.12 & 0.81 & 0.27 & 0. & 0.48 & -0.01 & 0.14 & 0.75 & 0.13 & $-c$ & 0.57 & -0.06 & 0.09 \\
\hline High & 0.21 & -0.52 & -0.65 & 0.15 & -0.63 & -0.29 & 0.62 & -0.05 & -0.12 & 0.31 & -0.29 & -0.03 & 0.41 & -0.36 & -0.45 & 0.39 & -0.36 & -0.05 \\
\hline $\mathrm{H}-\mathrm{L} \quad \mathrm{AG}$ & -1.60 & -1.68 & -1.40 & -0.81 & -0.86 & -0.40 & -0.71 & -0.82 & -0.57 & -0.32 & -0.45 & -0.03 & -0.49 & -0.63 & -0.31 & -0.37 & -0.55 & -0.05 \\
\hline \multirow[t]{3}{*}{$t_{\mathrm{H}-\mathrm{L}}$} & -8.48 & -9.17 & -7.94 & -3.06 & -3.30 & -1.52 & -4.92 & -6.15 & -4.39 & -2.08 & -3.09 & -0.25 & -3.53 & -4.74 & -2.72 & -1.88 & -2.89 & -0.31 \\
\hline & \multicolumn{6}{|c|}{ High payout ratio (least constrained) } & \multicolumn{6}{|c|}{ Without bond rating (constrained) } & \multicolumn{6}{|c|}{ High $W W$ (most constrained) } \\
\hline & $r^{e w}$ & $\alpha^{e w}$ & $\alpha_{F F}^{e w}$ & $r^{v w}$ & $\alpha^{v w}$ & $\alpha_{F F}^{v w}$ & $r^{e w}$ & $\alpha^{e w}$ & $\alpha_{F F}^{e w}$ & $r^{v w}$ & $\alpha^{v w}$ & $\alpha_{F F}^{v w}$ & $r^{e w}$ & $\alpha^{e w}$ & $\alpha_{F F}^{e w}$ & $r^{v w}$ & $\alpha^{v w}$ & $\alpha_{F F}^{v w}$ \\
\hline Lo & 1.07 & 0.61 & 0. & & 0.22 & 0 . & 1.62 & 1. & & 9 & -0 & $\overline{-0}$ & 2.13 & 1 & $\overline{1.12}$ & 0.59 & -0.31 & -0.36 \\
\hline 2 & 0.77 & 0.37 & 0.06 & & 0.16 & 0.02 & 1.16 & 0.68 & 0. & 0.5 & 0.08 & -0.12 & 1.93 & 1.30 & 1.02 & 0.99 & 0.20 & 0.15 \\
\hline 2 & 0.74 & 0.34 & 0.0 & 0.40 & 0.03 & -0.04 & 0.88 & 0.41 & 0. & 0.53 & 0.08 & -0.03 & 1.49 & 0.88 & 0.62 & 0.94 & 0.15 & 0.12 \\
\hline 4 & 0.67 & 0.25 & 0.02 & 0.50 & 0.08 & 0.08 & 0.73 & 0.20 & -0.12 & 0.33 & -0.22 & -0.24 & 1.02 & 0.39 & 0.12 & 0.53 & -0.28 & -0.35 \\
\hline High & 0.56 & 0.06 & -0.16 & 0.42 & -0.09 & 0.08 & 0.12 & -0.51 & -0.76 & -0.14 & -0.80 & -0.63 & 0.47 & -0.31 & -0.47 & -0.03 & -0.92 & -0.83 \\
\hline$t_{\mathrm{H}-\mathrm{L}}$ & \multicolumn{6}{|c|}{ Low-minus-high payout ratio } & \multicolumn{6}{|c|}{ Without-minus-with bond rating } & \multicolumn{6}{|c|}{ High-minus-low $W W$} \\
\hline $\mathrm{H}-\mathrm{L} A G$ & -1.09 & -1.13 & -1.02 & -0.58 & -0.55 & -0.47 & -0.79 & -0.74 & -0.86 & -0.40 & -0.34 & -0.43 & $\begin{array}{l}-17 \\
\end{array}$ & -1.03 & -1.27 & -0.24 & -0.06 & -0.42 \\
\hline$t_{\mathrm{H}-\mathrm{L}}$ & -5.64 & -5.91 & -5.59 & -0.90 & -0.84 & -0.75 & -7.23 & -6.97 & -8.03 & -2.62 & -2.44 & -3.07 & -4.26 & -3.97 & -4.45 & -0.45 & 0.03 & -0.71 \\
\hline
\end{tabular}


At the end of June of year $t$, we first split the sample into three equal-numbered subsamples by payout ratio (Panel A), two subsamples by bond ratings (Panel $\mathrm{B}$ ), and three equal-numbered subsamples by the $W W$ index (Panel C) using accounting variables in fiscal year ending in calendar year $t-1$. In Panels A and B, the sample is from July 1963 to December 2006 (534 months). In Panel C, the sample is from July 1976 to December 2006 (378 months) because of the quarterly data limitation for long-term debt in the construction of the $W W$ index. Payout ratio is the sum of dividends and stock repurchase divided by operating income. In Panel B, the constrained subsample contains all the firms with debt outstanding but without a bond rating, and the unconstrained subsample contains all the firms whose bonds are rated. See Section 3 for details of constructing the $W W$ index. Within each subsample, firms are sorted into five equal-numbered portfolios based on net stock issues (NS). NS is the change in the natural logarithms of the number of shares outstanding adjusted for splits to capture the effect of share repurchases and seasoned equity offerings. The high-minus-low portfolio (H-L NS) is long in the high NS portfolio and short in the low NS portfolio. Portfolio returns are computed over the period from July of year $t$ to June of year $t+1$. The portfolios are rebalanced at the end of each June. Excess return $(r)$ is the difference between portfolio returns and the one-month Treasury bill rate. The CAPM alphas $(\alpha)$ and Fama-French alphas $\left(\alpha_{F F}\right)$ are the intercepts from regressing portfolio excess returns on the market factor and the three Fama-French factors, respectively. The superscript $e w$ denotes equal-weighted returns and $v w$ denotes value-weighted returns. The $t$-statistics are adjusted for heteroscedasticity and autocorrelations.

\begin{tabular}{|c|c|c|c|c|c|c|c|c|c|c|c|c|c|c|c|c|c|c|}
\hline & \multirow{2}{*}{\multicolumn{6}{|c|}{$\begin{array}{l}\text { Panel A: Subsamples by payout ratio } \\
\text { Low payout ratio (most constrained) }\end{array}$}} & \multirow{2}{*}{\multicolumn{6}{|c|}{$\begin{array}{c}\text { Panel B: Subsamples by bond rating } \\
\text { With bond rating (unconstrained) }\end{array}$}} & \multicolumn{6}{|c|}{ Panel C: Subsamples by the $W W$ index } \\
\hline & & & & & & & & & & & & & \multicolumn{6}{|c|}{ Low $W W$ (least constrained) } \\
\hline & $r^{e w}$ & $\alpha^{e w}$ & $\alpha_{F F}^{e w}$ & $r^{v w}$ & $\alpha^{v w}$ & $\alpha_{F F}^{v w}$ & $r^{e w}$ & $\alpha^{e w}$ & $\alpha_{F F}^{e w}$ & $r^{v w}$ & $\alpha^{v w}$ & $\alpha_{F F}^{v w}$ & $r^{e w}$ & $\alpha^{e w}$ & $\alpha_{F F}^{e w}$ & $r^{v w}$ & $\alpha^{v w}$ & $\alpha_{F F}^{v w}$ \\
\hline Low & 1.56 & 1.00 & 0.57 & 0.70 & 0.10 & -0.17 & 1.08 & 0.60 & 0.28 & 0.63 & 0.20 & 0.11 & 0.89 & 0.34 & -0.01 & 0.81 & 0.28 & 0.17 \\
\hline 2 & 1.35 & 0.74 & 0.37 & 0.84 & 0.20 & 0.09 & 1.02 & 0.56 & 0.23 & 0.44 & 0.03 & -0.03 & 0.74 & 0.19 & -0.17 & 0.50 & -0.04 & -0.03 \\
\hline 3 & 1.08 & 0.40 & 0.17 & 0.59 & -0.12 & -0.02 & 0.87 & 0.34 & 0.16 & 0.50 & 0.02 & 0.09 & 0.77 & 0.17 & -0.13 & 0.56 & -0.02 & 0.04 \\
\hline 4 & 0.79 & 0.07 & -0.13 & 0.52 & -0.27 & 0.03 & 0.92 & 0.33 & 0.22 & 0.45 & -0.07 & 0.09 & 0.79 & 0.13 & -0.08 & 0.64 & -0.04 & 0.08 \\
\hline High & 0.49 & -0.24 & -0.38 & -0.05 & -0.81 & -0.55 & 0.59 & -0.02 & -0.13 & 0.21 & -0.31 & -0.27 & 0.44 & -0.28 & -0.45 & 0.32 & -0.34 & -0.27 \\
\hline $\mathrm{H}-\mathrm{L} \mathrm{NS}$ & -1.08 & -1.24 & -0.96 & -0.75 & -0.90 & -0.38 & -0.49 & -0.62 & -0.41 & -0.42 & -0.50 & -0.37 & -0.45 & -0.62 & -0.45 & -0.48 & -0.63 & -0.44 \\
\hline \multirow[t]{3}{*}{$t_{\mathrm{H}-\mathrm{L}}$} & -6.95 & -9.00 & -7.41 & -3.37 & -4.23 & -1.96 & -3.63 & -4.97 & -3.70 & -3.38 & -4.08 & -3.30 & -2.81 & -4.06 & -3.02 & -2.98 & -3.88 & -2.93 \\
\hline & \multicolumn{6}{|c|}{ High payout ratio (least constrained) } & \multicolumn{6}{|c|}{ Without bond rating (constrained) } & \multicolumn{6}{|c|}{ High $W W$ (most constrained) } \\
\hline & $r^{e w}$ & $\alpha^{e w}$ & $\alpha_{F F}^{e w}$ & $r^{v w}$ & $\alpha^{v w}$ & $\overline{\alpha_{F F}^{v w}}$ & $r^{e w}$ & $\alpha^{e w}$ & $\alpha_{F F}^{e w}$ & $r^{v w}$ & $\alpha^{v w}$ & $\alpha_{F F}^{v w}$ & $r^{e w}$ & $\alpha^{e w}$ & $\alpha_{F F}^{e w}$ & $r^{v w}$ & $\alpha^{v w}$ & $\alpha_{F F}^{v w}$ \\
\hline Low & 1.10 & 0.65 & 0.30 & 0.74 & 0.31 & $\overline{0.11}$ & 1.21 & 0.75 & 0.31 & 0.69 & 0.25 & 0.02 & 1.88 & 1.33 & 1.02 & 1.19 & 0.53 & 0.35 \\
\hline 2 & 0.81 & 0.40 & 0.09 & 0.59 & 0.17 & 0.10 & 1.10 & 0.63 & 0.19 & 0.35 & -0.11 & -0.35 & 1.63 & 1.04 & 0.70 & 0.77 & 0.06 & -0.14 \\
\hline 3 & 0.69 & 0.27 & -0.02 & 0.41 & 0.02 & -0.01 & 0.94 & 0.41 & 0.07 & 0.51 & 0.00 & -0.03 & 1.46 & 0.77 & 0.53 & 0.78 & -0.05 & -0.07 \\
\hline 4 & 0.73 & 0.29 & 0.06 & 0.53 & 0.08 & 0.13 & 0.81 & 0.23 & -0.01 & 0.36 & -0.25 & -0.16 & 1.22 & 0.44 & 0.28 & 0.48 & -0.45 & -0.36 \\
\hline High & 0.47 & 0.01 & -0.22 & 0.23 & -0.20 & -0.24 & 0.38 & -0.26 & -0.46 & -0.33 & -1.00 & -0.85 & 0.79 & -0.02 & -0.11 & -0.15 & -1.06 & -0.94 \\
\hline $\mathrm{H}-\mathrm{L} \mathrm{NS}$ & -0.63 & -0.64 & -0.52 & -0.51 & -0.50 & -0.35 & -0.83 & -1.01 & -0.77 & -1.02 & -1.25 & -0.87 & -1.09 & -1.34 & -1.13 & -1.34 & -1.60 & -1.29 \\
\hline \multirow[t]{2}{*}{$t_{\mathrm{H}-\mathrm{L}}$} & -6.96 & -6.91 & -5.49 & -4.50 & -4.36 & -3.11 & -4.99 & -6.97 & -6.12 & -5.01 & -6.85 & -5.74 & -5.47 & -7.64 & -6.93 & -5.79 & -7.54 & -7.07 \\
\hline & \multicolumn{6}{|c|}{ Low-minus-high payout ratio } & \multicolumn{6}{|c|}{ Without-minus-with bond rating } & \multicolumn{6}{|c|}{ High-minus-low $W W$} \\
\hline $\mathrm{H}-\mathrm{L} \mathrm{NS}$ & -0.45 & -0.60 & -0.44 & -0.24 & -0.40 & -0.03 & -0.34 & -0.39 & -0.36 & -0.60 & -0.75 & -0.50 & -0.64 & -0.72 & -0.68 & -0.86 & -0.97 & -0.85 \\
\hline$t_{\mathrm{H}-\mathrm{L}}$ & -2.08 & -3.58 & -2.43 & -1.78 & -2.59 & -1.21 & -2.75 & -3.52 & -3.16 & -3.97 & -5.29 & -3.61 & -3.11 & -3.49 & -2.59 & -3.83 & -4.32 & -3.69 \\
\hline
\end{tabular}


Table 4 : The Accrual Effect Across Subsamples Split by Payout Ratio, Bond Rating, and Whited-Wu ( $W W)$ Index

At the end of June of year $t$, we first split the sample into three equal-numbered subsamples by payout ratio (Panel A), two subsamples by bond ratings (Panel $\mathrm{B}$ ), and three equal-numbered subsamples by the $W W$ index (Panel C) using accounting variables in fiscal year ending in calendar year $t-1$. In Panels A and B, the sample is from July 1963 to December 2006 (534 months). In Panel C, the sample is from July 1976 to December 2006 (378 months) because of the quarterly data limitation for long-term debt in the construction of the $W W$ index. Payout ratio is the sum of dividends and stock repurchase divided by operating income. In Panel B, the constrained subsample contains all the firms with debt outstanding but without a bond rating, and the unconstrained subsample contains all the firms whose bonds are rated. See Section 3 for details of constructing the $W W$ index. Within each subsample, firms are sorted into five equal-numbered portfolios based on accruals (AC). AC is the changes in non-cash working capital minus depreciation expense scaled by average total assets in the recent two years. The high-minus-low portfolio (H-L AC) is long in the high AC quintile and short in the low AC portfolio. Portfolio returns are computed over the period from July of year $t$ to June of year $t+1$. The portfolios are rebalanced at the end of each June. Excess return $(r)$ is the difference between portfolio returns and the one-month Treasury bill rate. The CAPM alphas $(\alpha)$ and Fama-French alphas $\left(\alpha_{F F}\right)$ are the intercepts from regressing portfolio excess returns on the market factor and the three Fama-French factors, respectively. The superscript ew denotes equal-weighted returns and $v w$ denotes value-weighted returns. The $t$-statistics are adjusted for heteroscedasticity and autocorrelations.

\begin{tabular}{|c|c|c|c|c|c|c|c|c|c|c|c|c|c|c|c|c|c|c|}
\hline & \multicolumn{6}{|c|}{ Panel A: Subsamples by payout ratio } & \multicolumn{6}{|c|}{ Panel B: Subsamples by bond rating } & \multicolumn{6}{|c|}{ Panel C: Subsamples by the $W W$ index } \\
\hline & \multicolumn{6}{|c|}{ Low payout ratio (most constrained) } & \multicolumn{6}{|c|}{ With bond rating (unconstrained) } & \multicolumn{6}{|c|}{ Low $W W$ (least constrained) } \\
\hline & $r^{e w}$ & $\alpha^{e w}$ & $\alpha_{F F}^{e w}$ & $r^{v w}$ & $\alpha^{v w}$ & $\alpha_{F F}^{v w}$ & $r^{e w}$ & $\alpha^{e w}$ & $\alpha_{F F}^{e w}$ & $r^{v w}$ & $\alpha^{v w}$ & $\alpha_{F F}^{v w}$ & $r^{e w}$ & $\alpha^{e w}$ & $\alpha_{F F}^{e w}$ & $r^{v w}$ & $\alpha^{v w}$ & $\alpha_{F F}^{v w}$ \\
\hline Low & 1.43 & 0.76 & 0.42 & 0.71 & -0.04 & 0.08 & 1.17 & 0.61 & 0.36 & 0.49 & -0.01 & 0.11 & 0.85 & 0.16 & -0.09 & 0.63 & -0.04 & 0.10 \\
\hline 2 & 1.29 & 0.66 & 0.35 & 0.57 & -0.14 & 0.04 & 0.99 & 0.47 & 0.22 & 0.46 & 0.02 & 0.03 & 1.01 & 0.39 & 0.14 & 0.64 & 0.07 & 0.08 \\
\hline 3 & 1.08 & 0.45 & 0.13 & 0.54 & -0.17 & -0.07 & 0.96 & 0.45 & 0.19 & 0.60 & 0.14 & 0.17 & 0.67 & 0.14 & -0.24 & 0.53 & 0.03 & -0.10 \\
\hline 4 & 1.01 & 0.35 & 0.08 & 0.63 & -0.12 & 0.03 & 0.91 & 0.38 & 0.19 & 0.42 & -0.04 & 0.05 & 0.67 & 0.08 & -0.27 & 0.53 & -0.05 & -0.11 \\
\hline High & 0.64 & -0.05 & -0.32 & 0.24 & -0.53 & -0.37 & 0.87 & 0.26 & 0.07 & 0.28 & -0.30 & -0.09 & 0.66 & -0.05 & -0.30 & 0.46 & -0.26 & -0.16 \\
\hline $\mathrm{H}-\mathrm{L} \mathrm{AC}$ & -0.79 & -0.82 & -0.75 & -0.47 & -0.49 & -0.46 & -0.30 & -0.35 & -0.29 & -0.21 & -0.29 & -0.20 & -0.26 & -0.27 & -0.25 & -0.25 & -0.29 & -0.26 \\
\hline \multirow[t]{3}{*}{$t_{\mathrm{H}-\mathrm{L}}$} & -6.12 & -6.46 & -5.74 & -2.17 & -2.30 & -2.01 & -3.25 & -4.01 & -3.13 & -1.52 & -2.16 & -1.49 & -2.93 & -3.05 & -2.65 & -1.68 & -1.89 & -1.62 \\
\hline & \multicolumn{6}{|c|}{ High payout ratio (least constrained) } & \multicolumn{6}{|c|}{ Without bond rating (constrained) } & \multicolumn{6}{|c|}{ High $W W$ (most constrained) } \\
\hline & $r^{e w}$ & $\alpha^{e w}$ & $\alpha_{F F}^{e w}$ & $r^{v w}$ & $\alpha^{v w}$ & $\alpha_{F F}^{v w}$ & $r^{e w}$ & $\alpha^{e w}$ & $\alpha_{F F}^{e w}$ & $r^{v w}$ & $\alpha^{v w}$ & $\alpha_{F F}^{v w}$ & $r^{e w}$ & $\alpha^{e w}$ & $\alpha_{F F}^{e w}$ & $r^{v w}$ & $\alpha^{v w}$ & $\alpha_{F F}^{v w}$ \\
\hline Low & 1.02 & 0.55 & 0.24 & 0.44 & -0.02 & 0.05 & 1.21 & 0.64 & 0.30 & 0.37 & -0.21 & -0.22 & 1.76 & 1.01 & 0.68 & 0.43 & -0.49 & -0.49 \\
\hline 2 & 0.88 & 0.43 & 0.14 & 0.57 & 0.14 & 0.09 & 1.13 & 0.63 & 0.29 & 0.39 & -0.13 & -0.16 & 1.73 & 1.09 & 0.90 & 0.82 & 0.01 & 0.04 \\
\hline 3 & 0.83 & 0.37 & 0.06 & 0.59 & 0.14 & 0.10 & 0.93 & 0.42 & 0.05 & 0.39 & -0.15 & -0.22 & 1.46 & 0.80 & 0.52 & 0.70 & -0.12 & -0.10 \\
\hline 4 & 0.78 & 0.32 & 0.03 & 0.43 & 0.00 & 0.01 & 0.83 & 0.29 & -0.05 & 0.31 & -0.27 & -0.23 & 1.31 & 0.52 & -0.12 & 0.58 & -0.33 & -0.72 \\
\hline High & 0.68 & 0.17 & -0.11 & 0.29 & -0.21 & -0.17 & 0.45 & -0.14 & -0.47 & 0.02 & -0.61 & -0.63 & 0.99 & 0.26 & 0.01 & 0.22 & -0.66 & -0.65 \\
\hline $\mathrm{H}-\mathrm{L} \mathrm{AC}$ & -0.34 & -0.37 & -0.35 & -0.15 & -0.19 & -0.23 & -0.76 & -0.78 & -0.77 & -0.35 & -0.40 & -0.41 & -0.77 & -0.75 & -0.67 & -0.21 & -0.17 & -0.17 \\
\hline \multirow[t]{2}{*}{$t_{\mathrm{H}-\mathrm{L}}$} & -4.77 & -5.47 & -4.95 & -1.05 & -1.34 & -1.53 & -7.31 & -7.80 & -7.33 & -2.12 & -2.45 & -2.43 & -4.83 & -4.83 & -4.14 & -0.99 & -0.83 & -0.75 \\
\hline & \multicolumn{6}{|c|}{ Low-minus-high payout ratio } & \multicolumn{6}{|c|}{ Without-minus-with bond rating } & \multicolumn{6}{|c|}{ High-minus-low $W W$} \\
\hline $\mathrm{H}-\mathrm{L} \mathrm{AC}$ & -0.45 & -0.45 & -0.40 & -0.32 & -0.30 & -0.23 & -0.46 & -0.43 & -0.48 & -0.14 & -0.11 & -0.21 & -0.51 & -0.48 & -0.42 & 0.04 & 0.12 & 0.09 \\
\hline$t_{\mathrm{H}-\mathrm{L}}$ & -3.49 & -3.47 & -2.98 & -1.39 & -1.31 & -0.95 & -4.62 & -4.39 & -4.99 & -0.83 & -0.67 & -1.25 & -3.19 & -3.05 & -2.59 & 0.17 & 0.49 & 0.38 \\
\hline
\end{tabular}


Table 5 : The Asset Growth, Net Stock Issues, and Accrual Effects Across Subsamples Split by O-score (July 1963-December 2006, 534 Months)

At the end of June of year $t$, we first split the sample into three equal-numbered subsamples by $O$-score measured in fiscal year ending in calendar year $t-1$. The definition of $O$-score is described in Section 3. Within each subsample, firms are sorted into five equal-numbered portfolios based on asset growth (AG, Panel A), net stock issues (NS, Panel B), and accruals (AC, Panel C). AG is defined as the change in total assets divided by lagged total assets. NS is the change in the natural logarithms of the number of shares outstanding adjusted for splits to capture the effect of share repurchases and seasoned equity offerings. AC is the changes in non-cash working capital minus depreciation expense scaled by average total assets in the recent two years. Portfolio returns are computed over the period from July of year $t$ to June of year $t+1$. The portfolios are rebalanced at the end of each June. Excess return $(r)$ is the difference between portfolio returns and the one-month Treasury bill rate. The CAPM alphas $(\alpha)$ and Fama-French alphas $\left(\alpha_{F F}\right)$ are the intercepts from regressing portfolio excess returns on the market factor and the three Fama-French factors, respectively. The superscript $e w$ denotes equal-weighted returns and $v w$ denotes value-weighted returns. The $t$-statistics are adjusted for heteroscedasticity and autocorrelations.

\begin{tabular}{|c|c|c|c|c|c|c|c|c|c|c|c|c|c|c|c|c|c|c|}
\hline & \multicolumn{6}{|c|}{ Panel A: Asset growth (AG) } & \multicolumn{6}{|c|}{ Panel B: Net stock issues (NS) } & \multicolumn{6}{|c|}{ Panel C: Accruals (AC) } \\
\hline & \multicolumn{6}{|c|}{ Low $O$-score (least distressed) } & \multicolumn{6}{|c|}{ Low $O$-score (least distressed) } & \multicolumn{6}{|c|}{ Low $O$-score (least distressed) } \\
\hline & $r^{e w}$ & $\alpha^{e w}$ & $\alpha_{F F}^{e w}$ & $r^{v w}$ & $\alpha^{v w}$ & $\alpha_{F F}^{v w}$ & $r^{e w}$ & $\alpha^{e w}$ & $\alpha_{F F}^{e w}$ & $r^{v w}$ & $\alpha^{v w}$ & $\overline{\alpha_{F F}^{v w}}$ & $r^{e w}$ & $\alpha^{e w}$ & $\alpha_{F F}^{e w}$ & $r^{v w}$ & $\alpha^{v w}$ & $\alpha_{F F}^{v w}$ \\
\hline Low & 1.03 & 0.55 & 0.25 & 0.68 & 0.24 & 0.10 & 1.03 & 0.57 & 0.29 & 0.71 & 0.27 & 0.21 & 0.97 & 0.46 & 0.32 & 0.44 & -0.07 & 0.14 \\
\hline 2 & 0.88 & 0.42 & 0.19 & 0.44 & 0.03 & & 0.79 & 0.35 & 0.07 & 0.40 & -0.01 & -0.02 & 0.80 & 0.31 & 0.13 & 0.52 & 0.08 & 0.10 \\
\hline 3 & 0.82 & 0.32 & 0.17 & 0.49 & 0.06 & 0. & 0.83 & 0.31 & 0.17 & 0.54 & 0.06 & 0.1 & 0.82 & 0.32 & 0.16 & 0.54 & 0.08 & 0.20 \\
\hline 4 & 0.76 & 0.21 & 0.13 & 0.52 & 0.01 & 0.26 & 0.83 & 0.25 & 0.22 & 0.58 & 0.04 & 0.28 & 0.78 & 0.24 & 0.17 & 0.34 & -0.16 & 0.03 \\
\hline High & 0.43 & -0.25 & -0.20 & 0.33 & -0.28 & 0.10 & 0.40 & -0.25 & -0.23 & 0.17 & -0.36 & -0.16 & 0.55 & -0.07 & -0.18 & 0.27 & -0.34 & -0.09 \\
\hline $\mathrm{H}-\mathrm{L}$ & -0.60 & -0.80 & -0.45 & -0.34 & -0.52 & 0.00 & -0.63 & -0.83 & -0.52 & -0.53 & -0.64 & -0.37 & -0.42 & -0.53 & -0.50 & -0.16 & -0.28 & -0.22 \\
\hline \multirow[t]{3}{*}{$t_{\mathrm{H}-\mathrm{L}}$} & -4.32 & -6.82 & -4.64 & -1.83 & -3.00 & & & -6.76 & -5.12 & -3.85 & -4.74 & -3 & & -5.94 & -5.50 & -0.96 & -1.70 & -1.39 \\
\hline & \multicolumn{6}{|c|}{ High $O$-score (most distressed) } & \multicolumn{6}{|c|}{ High $O$-score (most distressed) } & \multicolumn{6}{|c|}{ High $O$-score (most distressed) } \\
\hline & $r^{e w}$ & $\alpha^{e w}$ & $\alpha_{F F}^{e w}$ & $r^{v w}$ & $\alpha^{v w}$ & $\alpha_{F F}^{v w}$ & $r^{e w}$ & $\alpha^{e w}$ & $\alpha_{F F}^{e w}$ & $r^{v w}$ & $\alpha^{v w}$ & $\overline{\alpha_{F F}^{v w}}$ & $r^{e w}$ & $\alpha^{e w}$ & $\alpha_{F F}^{e w}$ & $r^{v w}$ & $\alpha^{v w}$ & $\alpha_{F F}^{v w}$ \\
\hline Low & 1.83 & 1.17 & 0.81 & 0.60 & -0.09 & -0.26 & 1.58 & 1.07 & 0.63 & 0.73 & 0.22 & -0.17 & 1.59 & 0.93 & $\overline{0.57}$ & 0.60 & -0.14 & -0.19 \\
\hline 2 & 1.40 & 0.86 & 0.55 & 0.67 & 0.10 & -0.03 & 1.25 & 0.72 & 0.28 & 0.52 & 0.03 & -0 & 1.30 & 0.72 & 0.36 & 0.48 & -0.17 & -0.26 \\
\hline 3 & 1.11 & 0.60 & 0.25 & 0.60 & 0.11 & -0.12 & 1.18 & 0.59 & 0.29 & 0.53 & -0.07 & -0.18 & 1.19 & 0.61 & 0.22 & 0.53 & -0.08 & -0.30 \\
\hline 4 & 0.81 & 0.26 & -0.08 & 0.44 & -0.15 & -0.25 & 0.93 & 0.28 & 0.05 & 0.50 & -0.17 & -0.17 & 1.02 & 0.42 & 0.05 & 0.43 & -0.20 & -0.42 \\
\hline High & 0.35 & -0.30 & -0.56 & 0.02 & -0.65 & -0.74 & 0.60 & -0.07 & -0.26 & -0.05 & -0.70 & -0.74 & 0.81 & 0.17 & -0.16 & 0.23 & -0.45 & -0.62 \\
\hline $\begin{array}{l}\mathrm{H}-\mathrm{L} \\
t_{\mathrm{H}-\mathrm{L}}\end{array}$ & \multicolumn{6}{|c|}{ High-minus-low $O$-score } & \multicolumn{6}{|c|}{ High-minus-low $O$-score } & \multicolumn{6}{|c|}{ High-minus-low $O$-score } \\
\hline $\mathrm{H}-\mathrm{L}$ & -0.88 & -0.67 & -0.92 & -0.24 & -0.05 & -0.48 & -0.35 & -0.31 & -0.37 & -0.24 & -0.28 & -0.20 & -0.36 & -0.23 & -0.23 & -0.20 & -0.03 & -0.21 \\
\hline$t_{\mathrm{H}-\mathrm{L}}$ & -3.96 & -3.31 & -5.08 & -0.85 & -0.17 & -1.94 & -2.51 & -2.25 & -2.55 & -1.15 & -1.40 & -0.98 & -2.14 & -1.43 & -1.67 & -0.78 & -0.13 & -0.79 \\
\hline
\end{tabular}


Table 6 : The Asset Growth, Net Stock Issues, and Accrual Effects Across Subsamples Split by Payout Ratio/Bond Rating/the Whited-Wu $(W W)$ Index and $O$-Score

On June 30 of year $t$, we split the sample into six subsamples by an independent three-by-two sort on payout ratio and $O$-score (Panel A) and on the $W W$ index and $O$-score (Panel C). In Panel B, we split the sample into four subsamples by an independent two-by-two sort on bond rating and $O$-score. The sort on bond rating categorizes firms into two groups: the constrained group containing the firms with debt outstanding but without a bond rating and the unconstrained group containing the firms whose bonds are rated. All the sorting variables are measured in fiscal year ending in calendar year $t-1$. The definition of $O$-score is described in Section 3. Within each subsample, firms are further sorted into five equal-numbered portfolios based on asset growth (AG), net stock issues (NS), and accruals (AC). Portfolio returns are computed over the period from July of year $t$ to June of year $t+1$. The portfolios are rebalanced at the end of each June. Excess return $(r)$ is the difference between portfolio returns and the onemonth T-bill rate. The CAPM alphas $(\alpha)$ and Fama-French alphas $\left(\alpha_{F F}\right)$ are the intercepts from regressing portfolio excess returns on the market factor and the Fama-French factors, respectively. The superscripts $e w$ and $v w$ denote equal-weighted and value-weighted returns, respectively. Statistics significant at the $5 \%$ level are denoted with *.

\begin{tabular}{|c|c|c|c|c|c|c|c|c|c|c|c|c|}
\hline \multirow{5}{*}{$\begin{array}{l}\mathrm{H}-\mathrm{L} \text { AG } \\
\mathrm{H}-\mathrm{L} \text { NS } \\
\mathrm{H}-\mathrm{L} \text { AC }\end{array}$} & \multicolumn{12}{|c|}{ Panel A: Subsamples by payout ratio and $O$-score (July 1963-December 2006, 534 Months) } \\
\hline & & $\alpha^{e w}$ & $\alpha_{F F}^{e w}$ & & & $\alpha_{F F}^{v w}$ & & & $\alpha_{F F}^{e w}$ & & & $\alpha_{F F}^{v w}$ \\
\hline & \multicolumn{6}{|c|}{ Low-minus-high payout ratio/low $O$-score } & \multicolumn{6}{|c|}{ Low-minus-high payout ratio/high $O$-score } \\
\hline & $\begin{array}{l}-0.69^{\star} \\
-0.27 \\
-0.39^{\star}\end{array}$ & $\begin{array}{l}-0.85^{\star} \\
-0.40^{\star} \\
-0.43^{\star}\end{array}$ & $\begin{array}{l}-0.64^{\star} \\
-0.25 \\
-0.40^{\star}\end{array}$ & & & $\begin{array}{l}-0 \\
-0 \\
-0\end{array}$ & $\begin{array}{l}-0.87^{\star} \\
-0.46^{\star} \\
-0.39^{\star}\end{array}$ & $\begin{array}{l}-0.88^{\star} \\
-0.65^{\star} \\
-0.35\end{array}$ & & & $\begin{array}{l}43 \\
59^{\star} \\
17\end{array}$ & $\begin{array}{l}.39 \\
.27 \\
.16\end{array}$ \\
\hline & \multicolumn{6}{|c|}{ Low payout ratio/high-minus-low $O$-score } & \multicolumn{6}{|c|}{ High payout ratio/high-minus-low $O$-score } \\
\hline $\begin{array}{l}\mathrm{H}-\mathrm{L} \text { AG } \\
\mathrm{H}-\mathrm{L} \text { NS } \\
\mathrm{H}-\mathrm{L} \text { AC }\end{array}$ & $\begin{array}{l}-0.50^{\star} \\
-0.25 \\
-0.22\end{array}$ & $\begin{array}{l}-0.29 \\
-0.22 \\
-0.11\end{array}$ & $\begin{array}{l}-0.52^{\star} \\
-0.27 \\
-0.17\end{array}$ & & & $\begin{array}{l}-0.40 \\
-0.34 \\
-0.10\end{array}$ & $\begin{array}{l}-0.32^{\star} \\
-0.06 \\
-0.21\end{array}$ & $\begin{array}{l}-0.26^{\star} \\
+0.03 \\
-0.19\end{array}$ & & & & $\begin{array}{l}-0.32 \\
-0.18 \\
-0.24\end{array}$ \\
\hline \multirow{3}{*}{$\mathrm{H}-\mathrm{L} \mathrm{AC}$} & \multicolumn{12}{|c|}{ Panel B: Subsamples by bond rating and $O$-score (July 1963-December 2006, 534 Months) } \\
\hline & $r^{e w}$ & $\alpha^{e w}$ & $\alpha_{F F}^{e w}$ & & $\alpha^{v w}$ & $\alpha_{F F}^{v w}$ & & $\alpha^{e w}$ & $\alpha_{F F}^{e w}$ & $r^{v w}$ & & $\alpha_{F F}^{v w}$ \\
\hline & \multicolumn{6}{|c|}{ Without-minus-with bond rating/low $O$-score } & \multicolumn{6}{|c|}{ Without-minus-with bond rating/high $O$-score } \\
\hline \multirow[t]{2}{*}{$\begin{array}{l}\mathrm{H}-\mathrm{L} \text { AG } \\
\mathrm{H}-\mathrm{L} \text { NS } \\
\mathrm{H}-\mathrm{L} \text { AC }\end{array}$} & $\begin{array}{l}-0.54^{\star} \\
-0.29^{\star} \\
-0.41^{\star}\end{array}$ & $\begin{array}{l}-0.55^{\star} \\
-0.35^{\star} \\
-0.39^{\star}\end{array}$ & $\begin{array}{l}-0.61^{\star} \\
-0.33^{\star} \\
-0.41^{\star}\end{array}$ & & & $\begin{array}{l}-0.41^{\star} \\
-0.63^{\star} \\
-0.34\end{array}$ & $\begin{array}{l}-0.59^{\star} \\
-0.39^{\star} \\
-0.54^{\star}\end{array}$ & $\begin{array}{l}-0.56^{\star} \\
-0.48^{\star} \\
-0.55^{\star}\end{array}$ & $\begin{array}{l}-0.59^{\star} \\
-0.52^{\star} \\
-0.64^{\star}\end{array}$ & $\begin{array}{l}-0.70^{\star} \\
-0.76^{\star} \\
-0.13\end{array}$ & & $\begin{array}{l}-0.60^{\star} \\
-0.67^{\star} \\
-0.20\end{array}$ \\
\hline & \multicolumn{6}{|c|}{ With bond rating/high-minus-low $O$-score } & \multicolumn{6}{|c|}{ Without bond rating/high-minus-low $O$-score } \\
\hline $\begin{array}{l}\mathrm{H}-\mathrm{L} \text { AG } \\
\mathrm{H}-\mathrm{L} \text { NS } \\
\mathrm{H}-\mathrm{L} \text { AC }\end{array}$ & $\begin{array}{l}-0.59^{\star} \\
-0.08 \\
-0.21\end{array}$ & $\begin{array}{l}-0.44^{\star} \\
-0.03 \\
-0.09\end{array}$ & $\begin{array}{l}-0.69^{\star} \\
-0.02 \\
-0.11\end{array}$ & $\begin{array}{l}-0.05 \\
-0.09 \\
-0.32\end{array}$ & $\begin{array}{l}+0.09 \\
-0.08 \\
-0.17\end{array}$ & $\begin{array}{l}-0.29 \\
-0.11 \\
-0.28\end{array}$ & $\begin{array}{l}-0.64^{\star} \\
-0.18 \\
-0.34^{\star}\end{array}$ & $\begin{array}{l}-0.45^{\star} \\
-0.16 \\
-0.25\end{array}$ & $\begin{array}{l}-0.67^{\star} \\
-0.21 \\
-0.33^{\star}\end{array}$ & $\begin{array}{l}-0.38 \\
-0.22 \\
-0.16\end{array}$ & $\begin{array}{l}-0.21 \\
-0.20 \\
-0.04\end{array}$ & $\begin{array}{l}-0.48 \\
-0.15 \\
-0.14\end{array}$ \\
\hline \multirow{3}{*}{$\mathrm{H}-\mathrm{L} \mathrm{AC}$} & \multicolumn{12}{|c|}{ Panel C: Subsamples by the $W W$ index and $O$-score (July 1976-December 2006, 378 Months) } \\
\hline & $r^{e w}$ & $\alpha^{e w}$ & $\alpha_{F F}^{e w}$ & & $\alpha^{v w}$ & $\alpha_{F F}^{v w}$ & & $\alpha^{e w}$ & $\alpha_{F F}^{e w}$ & $r^{v w}$ & $\alpha^{v w}$ & $\alpha_{F F}^{v w}$ \\
\hline & \multicolumn{6}{|c|}{ High-minus-low $W W /$ low $O$-score } & \multicolumn{6}{|c|}{ High-minus-low $W W /$ high $O$-score } \\
\hline $\begin{array}{l}\mathrm{H}-\mathrm{L} \text { AG } \\
\mathrm{H}-\mathrm{L} \text { NS } \\
\mathrm{H}-\mathrm{L} \text { AC }\end{array}$ & $\begin{array}{l}-0.75^{\star} \\
-0.56^{\star} \\
-0.30\end{array}$ & $\begin{array}{l}-0.77^{\star} \\
-0.62^{\star} \\
-0.35\end{array}$ & $\begin{array}{l}-1.05^{\star} \\
-0.70^{\star} \\
-0.32\end{array}$ & $\begin{array}{l}-0.42 \\
-0.77^{\star} \\
-0.34\end{array}$ & $\begin{array}{l}-0.38 \\
-0.90^{\star} \\
-0.34\end{array}$ & $\begin{array}{l}-0.96^{\star} \\
-0.94^{\star} \\
-0.33\end{array}$ & $\begin{array}{l}-1.07^{\star} \\
-0.66^{\star} \\
-0.52^{\star}\end{array}$ & $\begin{array}{l}-0.97^{\star} \\
-0.79^{\star} \\
-0.55^{\star}\end{array}$ & $\begin{array}{l}-1.06^{\star} \\
-0.71^{\star} \\
-0.44\end{array}$ & $\begin{array}{l}-0.09 \\
-0.83^{\star} \\
+0.25\end{array}$ & $\begin{array}{l}+0.10 \\
-0.96^{\star} \\
+0.25\end{array}$ & $\begin{array}{l}+0.04 \\
-0.76^{\star} \\
+0.40\end{array}$ \\
\hline $\mathrm{H}-\mathrm{L} \mathrm{AC}$ & \multicolumn{6}{|c|}{ Low $W W /$ high-minus-low $O$-score } & \multicolumn{6}{|c|}{ High $W W /$ high-minus-low $O$-score } \\
\hline $\begin{array}{l}\mathrm{H}-\mathrm{L} \text { AG } \\
\mathrm{H}-\mathrm{L} \text { NS } \\
\mathrm{H}-\mathrm{L} \text { AC }\end{array}$ & $\begin{array}{l}-0.30 \\
-0.20 \\
-0.02 \\
\end{array}$ & $\begin{array}{r}-0.17 \\
-0.11 \\
+0.13\end{array}$ & $\begin{array}{l}-0.37^{\star} \\
-0.14 \\
+0.05\end{array}$ & & $\begin{array}{l}-0 \\
-0 \\
+0 \\
\end{array}$ & $\begin{array}{l}-0.40 \\
-0.17 \\
-0.23 \\
\end{array}$ & $\begin{array}{l}0.62^{\star} \\
0.30 \\
0.24 \\
\end{array}$ & $\begin{array}{l}- \\
- \\
- \\
\end{array}$ & & $\begin{array}{r}+0.20 \\
-0.29 \\
+0.50 \\
\end{array}$ & $\begin{array}{l}99 \\
9 \\
\end{array}$ & $\begin{array}{l}+0.60 \\
+0.01 \\
+0.51 \\
\end{array}$ \\
\hline
\end{tabular}


Table 7 : The Asset Growth, Net Stock Issues, and Accrual Effects Across Subsamples Split by Trading Volume (July 1976-December 2006, 378 Months)

At the end of June of year $t$, we first split the sample into three equal-numbered subsamples by trading volume. The trading volume is the annual volume of trade in a firm's shares from July 1 of year $t-1$ to June 30 of year $t$ in millions of dollars from CRSP. Within each subsample, firms are sorted into five equal-numbered portfolios based on asset growth (AG, Panel A), net stock issues (NS, Panel B), and accruals (AC, Panel C). AG is the change in total assets divided by lagged total assets. NS is the change in the natural logarithms of the number of shares outstanding adjusted for splits to capture the effect of share repurchases and seasoned equity offerings. AC is the changes in non-cash working capital minus depreciation expense scaled by average total assets in the recent two years. Portfolio returns are computed over the period from July of year $t$ to June of year $t+1$. The portfolios are rebalanced at the end of each June. Excess return $(r)$ is the difference between portfolio returns and the one-month Treasury bill rate. The CAPM alphas $(\alpha)$ and Fama-French alphas $\left(\alpha_{F F}\right)$ are the intercepts from regressing portfolio excess returns on the market factor and the three Fama-French factors, respectively. The superscript ew denotes equal-weighted returns and $v w$ denotes value-weighted returns. The $t$-statistics are adjusted for heteroscedasticity and autocorrelations.

\begin{tabular}{|c|c|c|c|c|c|c|c|c|c|c|c|c|c|c|c|c|c|c|}
\hline & \multicolumn{6}{|c|}{ Panel A: Asset growth (AG) } & \multicolumn{6}{|c|}{ Panel B: Net stock issues (NS) } & \multicolumn{6}{|c|}{ Panel C: Accruals (AC) } \\
\hline & \multicolumn{6}{|c|}{ Low trading volume (most limited) } & \multicolumn{6}{|c|}{ Low trading volume (most limited) } & \multicolumn{6}{|c|}{ Low trading volume (most limited) } \\
\hline & $r^{e w}$ & $\alpha^{e w}$ & $\alpha_{F F}^{e w}$ & $r^{v w}$ & $\alpha^{v w}$ & $\overline{\alpha_{F F}^{v w}}$ & $r^{e w}$ & $\alpha^{e w}$ & $\alpha_{F F}^{e w}$ & $r^{v w}$ & $\alpha^{v w}$ & $\overline{\alpha_{F F}^{v w}}$ & $r^{e w}$ & $\alpha^{e w}$ & $\alpha_{F F}^{e w}$ & $r^{v w}$ & $\alpha^{v w}$ & $\alpha_{F F}^{v w}$ \\
\hline Low & 2.33 & 1.66 & 1.05 & 1.41 & 0.77 & 0.25 & 1.68 & 1.17 & 0.61 & 1.29 & 0.80 & 0.29 & 2.03 & 1.42 & 0.78 & 1.29 & 0.71 & 0.18 \\
\hline 2 & 1.79 & 1.26 & 0.69 & 1.19 & 0.68 & 0.16 & 1.73 & 1.20 & 0.61 & 1.23 & 0.75 & 0.31 & 1.81 & 1.28 & 0.73 & 1.33 & 0.85 & 0.40 \\
\hline 3 & 1.55 & 1.04 & 0.50 & 1.12 & 0.65 & 0.21 & 1.78 & 1.17 & 0.51 & 1.20 & 0.66 & 0.13 & 1.46 & 0.94 & 0.40 & 0.92 & 0.46 & 0.01 \\
\hline 4 & 1.35 & 0.82 & 0.28 & 1.21 & 0.72 & 0.32 & 1.56 & 0.95 & 0.48 & 1.18 & 0.60 & 0.21 & 1.51 & 0.95 & 0.41 & 1.14 & 0.63 & 0.21 \\
\hline High & 1.13 & 0.56 & 0.01 & 0.75 & 0.23 & -0.20 & 1.47 & 0.83 & 0.30 & 0.80 & 0.22 & -0.17 & 1.30 & 0.71 & 0.18 & 0.90 & 0.34 & -0.07 \\
\hline $\mathrm{H}-\mathrm{L}$ & -1.20 & -1.10 & -1.05 & -0.66 & -0.54 & -0.45 & -0.21 & -0.34 & -0.32 & -0.49 & -0.58 & -0.46 & -0.73 & -0.71 & -0.60 & -0.39 & -0.37 & -0.25 \\
\hline \multirow[t]{3}{*}{$t_{\mathrm{H}-\mathrm{L}}$} & -7.07 & -6.73 & -6.58 & -3.90 & -3.35 & -2.81 & -1.47 & -2.49 & -2.46 & -3.16 & -3.92 & -3.15 & -5.65 & -5.58 & -4.98 & -3.00 & -2.86 & -1.90 \\
\hline & \multicolumn{6}{|c|}{ High trading volume (least limited) } & \multicolumn{6}{|c|}{ High trading volume (least limited) } & \multicolumn{6}{|c|}{ High trading volume (least limited) } \\
\hline & $r^{e w}$ & $\alpha^{e w}$ & $\alpha_{F F}^{e w}$ & $r^{v w}$ & $\alpha^{v w}$ & $\overline{\alpha_{F F}^{v w}}$ & $r^{e w}$ & $\alpha^{e w}$ & $\alpha_{F F}^{e w}$ & $r^{v w}$ & $\alpha^{v w}$ & $\overline{\alpha_{F F}^{v w}}$ & $r^{e w}$ & $\alpha^{e w}$ & $\alpha_{F F}^{e w}$ & $r^{v w}$ & $\alpha^{v w}$ & $\alpha_{F F}^{v w}$ \\
\hline Low & 0.88 & 0.17 & $\overline{-0.04}$ & 0.74 & 0.19 & $\overline{0.04}$ & 0.85 & 0.26 & 0.00 & 0.68 & 0.17 & 0.09 & 0.77 & 0.01 & -0.02 & 0.62 & 0.02 & 0.16 \\
\hline 2 & 0.77 & 0.14 & -0.05 & 0.54 & 0.04 & -0.02 & 0.69 & 0.06 & -0.13 & 0.52 & -0.01 & 0.02 & 0.75 & 0.08 & -0.05 & 0.55 & 0.01 & 0.04 \\
\hline 3 & 0.73 & 0.08 & -0.02 & 0.59 & 0.05 & 0.10 & 0.70 & -0.01 & -0.04 & 0.60 & 0.00 & 0.15 & 0.75 & 0.09 & -0.07 & 0.65 & 0.10 & 0.10 \\
\hline 4 & 0.60 & -0.14 & -0.10 & 0.60 & -0.03 & 0.31 & 0.68 & -0.13 & -0.07 & 0.46 & -0.23 & 0.03 & 0.58 & -0.11 & -0.16 & 0.40 & -0.17 & -0.06 \\
\hline High & 0.17 & -0.70 & -0.59 & 0.26 & -0.49 & -0.23 & 0.23 & -0.62 & -0.55 & 0.32 & -0.34 & -0.25 & 0.30 & -0.52 & -0.51 & 0.27 & -0.45 & -0.20 \\
\hline $\mathrm{H}-\mathrm{L}$ & -0.72 & -0.87 & -0.55 & -0.48 & -0.68 & -0.27 & -0.62 & -0.87 & -0.55 & -0.36 & -0.51 & -0.34 & -0.47 & -0.53 & -0.49 & -0.35 & -0.46 & -0.36 \\
\hline \multirow[t]{2}{*}{$t_{\mathrm{H}-\mathrm{L}}$} & -5.01 & -6.50 & -4.78 & -2.83 & -4.28 & -2.05 & -3.36 & -5.39 & -4.36 & -2.59 & -3.98 & -3.01 & -4.40 & -5.16 & -4.40 & -2.56 & -3.53 & -2.66 \\
\hline & \multicolumn{6}{|c|}{ Low-minus-high volume } & \multicolumn{6}{|c|}{ Low-minus-high volume } & \multicolumn{6}{|c|}{ Low-minus-high volume } \\
\hline $\mathrm{H}-\mathrm{L}$ & -0.48 & -0.23 & -0.50 & -0.18 & 0.14 & -0.18 & 0.40 & 0.53 & 0.23 & -0.13 & -0.07 & -0.12 & -0.26 & -0.18 & -0.11 & -0.04 & 0.09 & 0.11 \\
\hline$t_{\mathrm{H}-\mathrm{L}}$ & -2.15 & -1.11 & -2.84 & -0.71 & 0.60 & -0.90 & 2.43 & 3.35 & 1.59 & -0.76 & -0.45 & -0.66 & -1.73 & -1.25 & -0.78 & -0.22 & 0.58 & 0.64 \\
\hline
\end{tabular}


Table 8: The Asset Growth, Net Stock Issues, and Accrual Effects Across Subsamples Split by Idiosyncratic Volatility (IVOL) (July 1976-December 2006, 378 Months)

At the end of June of year $t$, we first split the sample into three equal-numbered subsamples by $I V O L$. IVOL is the volatility of the residuals from regressing daily returns of a stock on the value-weighted market index over a maximum of 250 days ending on June 30 of year $t$. Within each subsample, firms are sorted into five equal-numbered portfolios based on asset growth (AG, Panel A), net stock issues (NS, Panel B), and accruals (AC, Panel C). AG is the change in total assets divided by lagged total assets. NS is the change in the natural logarithms of the number of shares outstanding adjusted for splits to capture the effect of share repurchases and seasoned equity offerings. AC is the changes in non-cash working capital minus depreciation expense scaled by average total assets in the recent two years. Portfolio returns are computed over the period from July of year $t$ to June of year $t+1$. The portfolios are rebalanced at the end of each June. Excess return $(r)$ is the difference between portfolio returns and the one-month Treasury bill rate. The CAPM alphas $(\alpha)$ and Fama-French alphas $\left(\alpha_{F F}\right)$ are the intercepts from regressing portfolio excess returns on the market factor and the three Fama-French factors, respectively. The superscript $e w$ denotes equal-weighted returns and $v w$ denotes value-weighted returns. The $t$-statistics are adjusted for heteroscedasticity and autocorrelations.

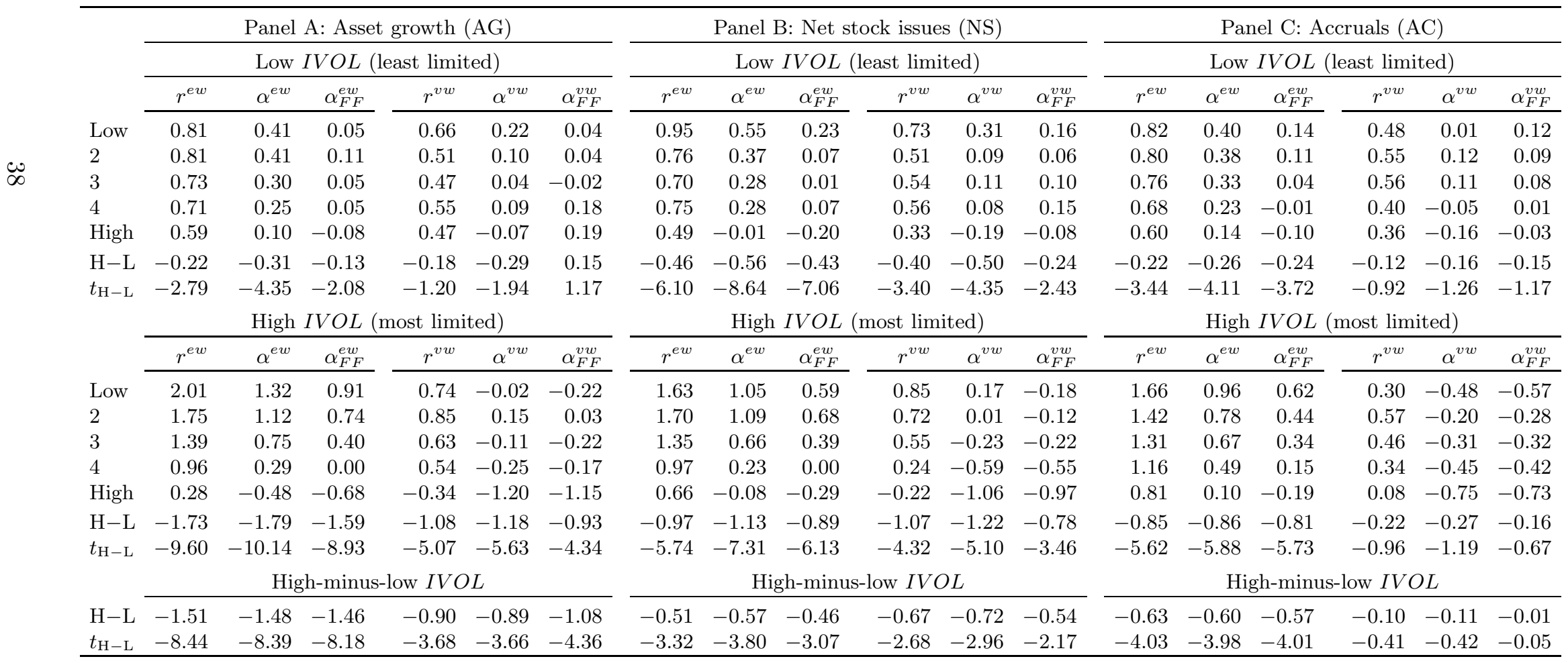


Table 9 : The Asset Growth, Net Stock Issues, and Accrual Effects Across Subsamples Split by Payout Ratio/Bond Rating/the Whited-Wu ( $W W$ ) Index and Trading Volume

On June 30 of year $t$, we split the sample into six subsamples by an independent three-by-two sort on payout ratio and trading volume (Panel A) and on the $W W$ index and trading volume (Panel C). In Panel B, we split the sample into four subsamples by an independent two-by-two sort on bond rating and trading volume. The sort on bond rating categorizes firms into two groups: the constrained group containing the firms with debt outstanding but without a bond rating and the unconstrained group containing the firms whose bonds are rated. All the sorting variables are measured in fiscal year ending in calendar year $t-1$. The trading volume is the annual volume of trade in a firm's shares from July 1 of year $t-1$ to June 30 of year $t$ in millions of dollars from CRSP. Within each subsample, firms are further sorted into five equal-numbered portfolios based on asset growth (AG), net stock issues (NS), and accruals (AC). Portfolio returns are computed over the period from July of year $t$ to June of year $t+1$. The portfolios are rebalanced at the end of each June. Excess return $(r)$ is the difference between portfolio returns and the onemonth T-bill rate. The CAPM alphas $(\alpha)$ and Fama-French alphas $\left(\alpha_{F F}\right)$ are the intercepts from regressing portfolio excess returns on the market factor and the Fama-French factors, respectively. The superscripts $e w$ and $v w$ denote equal-weighted and value-weighted returns, respectively. Statistics significant at the $5 \%$ level are denoted with *

\begin{tabular}{|c|c|c|c|c|c|c|c|c|c|c|c|c|}
\hline \multirow{5}{*}{$\begin{array}{l}\mathrm{H}-\mathrm{L} \text { AG } \\
\mathrm{H}-\mathrm{L} \text { NS } \\
\mathrm{H}-\mathrm{L} \text { AC }\end{array}$} & \multicolumn{12}{|c|}{ Panel A: Subsamples by payout ratio and volume (July 1963-December 2006, 534 Months) } \\
\hline & & & $\omega_{F F}$ & & & $u_{F F}$ & & & ${ }_{F F}$ & & & $\alpha_{F F}^{v w}$ \\
\hline & \multicolumn{6}{|c|}{ Low-minus-high payout ratio/low volume } & \multicolumn{6}{|c|}{ Low-minus-high payout ratio/high volume } \\
\hline & $\begin{array}{l}-0.70^{\star} \\
+0.03 \\
-0.51^{\star}\end{array}$ & $\begin{array}{l}-0.68^{\star} \\
-0.12 \\
-0.45^{\star}\end{array}$ & $\begin{array}{l}-0.72^{\star} \\
-0.12 \\
-0.41^{\star}\end{array}$ & & & & $\begin{array}{l}-0.79^{\star} \\
-0.52^{\star} \\
-0.39^{\star}\end{array}$ & $\begin{array}{l}-0.01 \\
-0.68^{\star} \\
-0.37^{\star}\end{array}$ & & $\begin{array}{l}47 \\
46^{\star}\end{array}$ & & $\begin{array}{l}.47 \\
.33 \\
.33\end{array}$ \\
\hline & \multicolumn{6}{|c|}{ Low payout ratio/low-minus-high volume } & \multicolumn{6}{|c|}{ High payout ratio/low-minus-high volume } \\
\hline $\begin{array}{l}\mathrm{H}-\mathrm{L} \text { AG } \\
\mathrm{H}-\mathrm{L} \text { NS } \\
\mathrm{H}-\mathrm{L} \text { AC }\end{array}$ & $\begin{array}{l}-0.29 \\
+0.49^{\star} \\
-0.29\end{array}$ & $\begin{array}{l}-0.15 \\
+0.51^{\star} \\
-0.24\end{array}$ & $\begin{array}{l}-0.31 \\
+0.36 \\
-0.17\end{array}$ & & & & $\begin{array}{l}-0.38^{\star} \\
-0.06 \\
-0.16\end{array}$ & & & & & $\begin{array}{l}-0.37^{\star} \\
-0.09 \\
+0.09\end{array}$ \\
\hline \multirow{3}{*}{$\mathrm{H}-\mathrm{L} \mathrm{AC}$} & \multicolumn{12}{|c|}{ Panel B: Subsamples by bond rating and volume (July 1963-December 2006, 534 Months) } \\
\hline & $r^{e w}$ & $\alpha^{e w}$ & $\alpha_{F F}^{e w}$ & & & $\alpha_{F F}^{v w}$ & & $\alpha^{e w}$ & $\alpha_{F F}^{e w}$ & $r^{v w}$ & $\alpha^{v w}$ & $\alpha_{F F}^{v w}$ \\
\hline & \multicolumn{6}{|c|}{ Without-minus-with bond rating/low volume } & \multicolumn{6}{|c|}{ Without-minus-with bond rating/high volume } \\
\hline \multirow[t]{2}{*}{$\begin{array}{l}\mathrm{H}-\mathrm{L} \text { AG } \\
\mathrm{H}-\mathrm{L} \text { NS } \\
\mathrm{H}-\mathrm{L} \text { AC }\end{array}$} & $\begin{array}{l}-0.57^{\star} \\
-0.27 \\
-0.34\end{array}$ & $\begin{array}{l}-0.55^{\star} \\
-0.30 \\
-0.33\end{array}$ & $\begin{array}{l}-0.63^{\star} \\
-0.22 \\
-0.41^{\star}\end{array}$ & & & & $\begin{array}{l}-0.60^{\star} \\
-0.36^{\star} \\
-0.32^{\star}\end{array}$ & $\begin{array}{l}-0.56^{\star} \\
-0.45^{\star} \\
-0.27^{\star}\end{array}$ & $\begin{array}{l}-0.71^{\star} \\
-0.36^{\star} \\
-0.45^{\star}\end{array}$ & $\begin{array}{l}-0.41^{\star} \\
-0.47^{\star} \\
-0.24\end{array}$ & & $\begin{array}{l}-0.40^{\star} \\
-0.40^{\star} \\
-0.37\end{array}$ \\
\hline & \multicolumn{6}{|c|}{ With bond rating/low-minus-high volume } & \multicolumn{6}{|c|}{ Without bond rating/low-minus-high volume } \\
\hline $\begin{array}{l}\mathrm{H}-\mathrm{L} \text { AG } \\
\mathrm{H}-\mathrm{L} \text { NS } \\
\mathrm{H}-\mathrm{L} \text { AC }\end{array}$ & $\begin{array}{l}-0.21 \\
+0.35^{\star} \\
-0.19\end{array}$ & & $\begin{array}{l}-0.23 \\
+0.22 \\
-0.11\end{array}$ & & & & & $\begin{array}{l}-0.04 \\
+0.52^{\star} \\
-0.19\end{array}$ & $\begin{array}{l}-0.15 \\
+0.36^{\star} \\
-0.08\end{array}$ & $\begin{array}{l}+0.28 \\
+0.04\end{array}$ & $\begin{array}{l}+0.34 \\
+0.42^{\star} \\
+0.11\end{array}$ & $\begin{array}{l}-0.03 \\
+0.27 \\
+0.15\end{array}$ \\
\hline \multirow{3}{*}{$\mathrm{H}-\mathrm{L} \mathrm{AC}$} & \multicolumn{12}{|c|}{ Panel C: Subsamples by the $W W$ index and volume (July 1976-December 2006, 378 Months) } \\
\hline & $r^{e w}$ & $\alpha^{e w}$ & $\alpha_{F F}^{e w}$ & & $\alpha^{v w}$ & & & $\alpha^{e w}$ & $\alpha_{F F}^{e w}$ & $r^{v w}$ & $\alpha^{v w}$ & $\alpha_{F F}^{v w}$ \\
\hline & \multicolumn{6}{|c|}{$\overline{\text { High-minus-low }} \overline{W W / \text { low volume }}$} & \multicolumn{6}{|c|}{ High-minus-low $W W /$ high volume } \\
\hline $\begin{array}{l}\mathrm{H}-\mathrm{L} \text { AG } \\
\mathrm{H}-\mathrm{L} \text { NS } \\
\mathrm{H}-\mathrm{L} \text { AC }\end{array}$ & $\begin{array}{l}-1.09^{\star} \\
-0.54^{\star} \\
-0.57^{\star}\end{array}$ & $\begin{array}{l}-1.03^{\star} \\
-0.69^{\star} \\
-0.48\end{array}$ & $\begin{array}{l}-0.98^{\star} \\
-0.56^{\star} \\
-0.34\end{array}$ & $\begin{array}{l}-0.03 \\
-0.38 \\
+0.04\end{array}$ & $\begin{array}{l}+0.05 \\
-0.56^{\star} \\
+0.13\end{array}$ & $\begin{array}{l}+ \\
- \\
+\end{array}$ & $\begin{array}{l}83^{\star} \\
37\end{array}$ & $\begin{array}{l}-0.49 \\
-0.77^{\star} \\
-0.19\end{array}$ & $\begin{array}{l}-0.66 \\
-0.71^{\star} \\
-0.21\end{array}$ & $\begin{array}{l}-0.40 \\
-0.66 \\
-0.49\end{array}$ & $\begin{array}{l}-0.19 \\
-0.68 \\
-0.28\end{array}$ & $\begin{array}{l}-0.44 \\
-0.51 \\
-0.36\end{array}$ \\
\hline $\mathrm{H}-\mathrm{L} \mathrm{AC}$ & \multicolumn{6}{|c|}{ Low $W W /$ low-minus-high volume } & \multicolumn{6}{|c|}{ High $W W /$ low-minus-high volume } \\
\hline $\begin{array}{l}\mathrm{H}-\mathrm{L} \text { AG } \\
\mathrm{H}-\mathrm{L} \text { NS } \\
\mathrm{H}-\mathrm{L} \text { AC }\end{array}$ & $\begin{array}{l}+0.13 \\
+0.37 \\
-0.04\end{array}$ & $\begin{array}{l}+0.27 \\
+0.48^{\star} \\
-0.08\end{array}$ & $\begin{array}{l}-0.16 \\
+0.29 \\
-0.14\end{array}$ & $\begin{array}{l}+0.12 \\
+0.16\end{array}$ & $\begin{array}{l}+0.35 \\
+0.26 \\
+0.13 \\
\end{array}$ & $\begin{array}{l}-0 \\
+0 \\
-0 \\
\end{array}$ & $\begin{array}{l}-0.11 \\
+0.74^{\star} \\
-0.24\end{array}$ & $\begin{array}{l}-0.13 \\
+0.67^{\star} \\
-0.36\end{array}$ & $\begin{array}{l}-0.34 \\
+0.73^{\star} \\
-0.23\end{array}$ & $\begin{array}{l}+0.72 \\
+0.47 \\
+0.70\end{array}$ & $\begin{array}{l}+0.74 \\
+0.44 \\
+0.55 \\
\end{array}$ & $\begin{array}{l}+0.44 \\
+0.25 \\
+0.63 \\
\end{array}$ \\
\hline
\end{tabular}


Table 10 : The Asset Growth, Net Stock Issues, and Accrual Effects Across Subsamples Split by Payout Ratio/Bond Rating/the Whited-Wu $(W W)$ Index and Idiosyncratic Volatility

$(I V O L)$

On June 30 of year $t$, we split the sample into six subsamples by an independent three-by-two sort on payout ratio and $I V O L$ (Panel A) and on the $W W$ index and IVOL (Panel C). IVOL is the volatility of the residuals from regressing daily returns of a stock on the value-weighted market portfolio returns over a maximum of 250 days ending on June 30 of year $t$. In Panel B, we split the sample into four subsamples by an independent two-by-two sort on bond rating and $I V O L$. The sort on bond rating categorizes firms into two groups: the constrained group containing the firms with debt outstanding but without a bond rating and the unconstrained group containing the firms whose bonds are rated. The sorting variables are measured in fiscal year ending in calendar year $t-1$. Within each subsample, firms are further sorted into five equal-numbered portfolios based on asset growth (AG), net stock issues (NS), and accruals (AC). Portfolio returns are computed over the period from July of year $t$ to June of year $t+1$. The portfolios are rebalanced at the end of each June. Excess return $(r)$ is the difference between portfolio returns and the onemonth T-bill rate. The CAPM alphas $(\alpha)$ and Fama-French alphas $\left(\alpha_{F F}\right)$ are the intercepts from regressing portfolio excess returns on the market factor and the Fama-French factors, respectively. The superscripts $e w$ and $v w$ denote equal-weighted and value-weighted returns, respectively. Statistics significant at the $5 \%$ level are denoted with *.

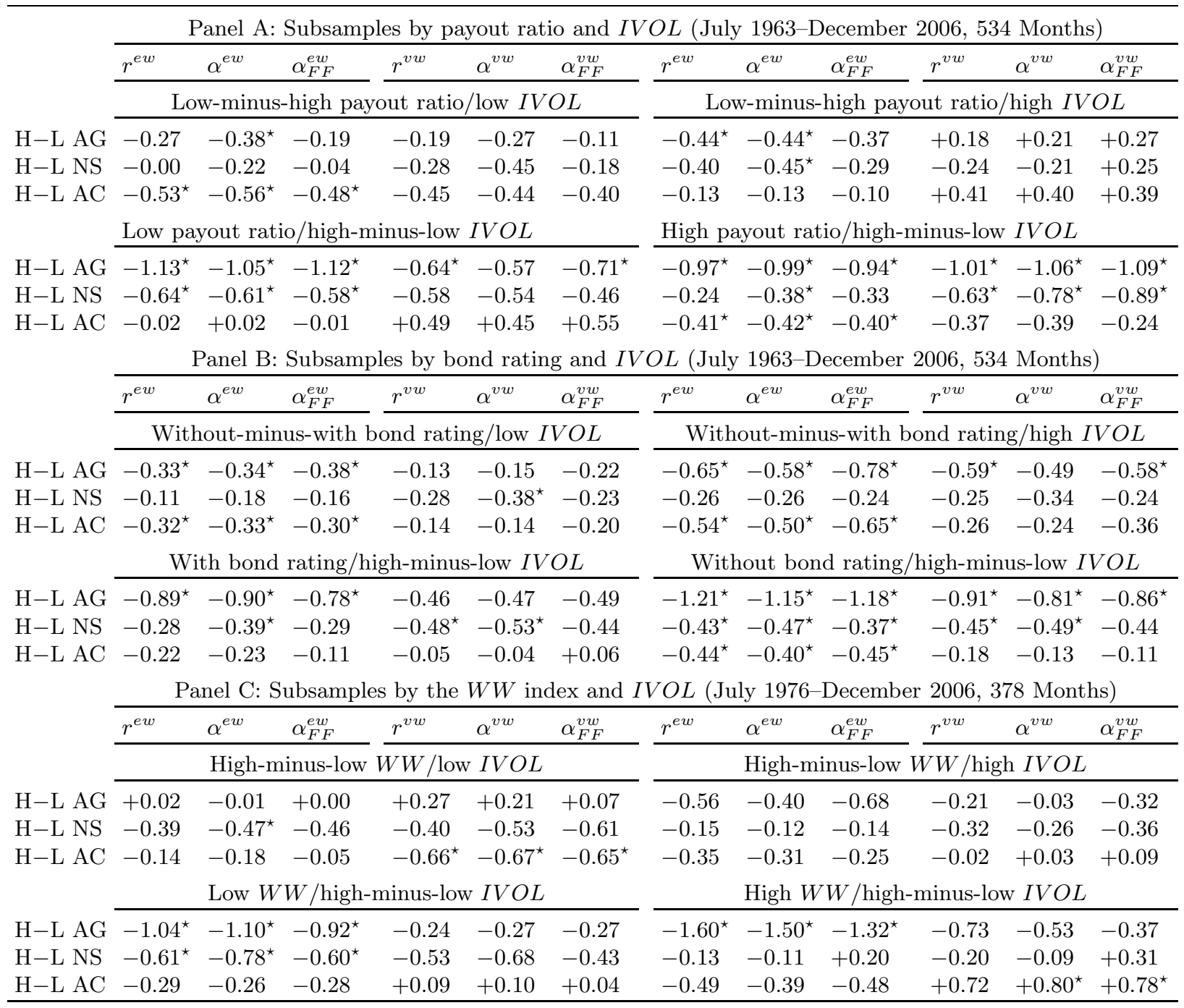




\section{A Supplementary Tests}

\section{A.1 The Impact of Financial Constraints on the Investment-to-Assets and Net Operating Assets Effects}

We measure investment-to-assets, I/A, as the change in property, plant, and equipment (Compustat annual item 7) plus change in inventories (item 3) divided by lagged total assets (item 6), following Lyandres, Sun, and Zhang (2008) and Chen and Zhang (2009). We use the change in property, plant, and equipment to capture investment in long-lived assets for operations over many years such as buildings, machinery, furniture, and other equipment. We use the change in inventories to capture investment in short-lived assets within a normal operating cycle such as merchandise, raw materials, supplies, and work in progress. Also, we have experimented with measuring investmentto-assets as capital expenditure (item 128) divided by lagged net property, plant, and equipment (item 8), following Xing (2008). The results are largely similar (not reported).

We measure net operating assets following Hirshleifer, Hou, Teoh, and Zhang (2004), who find that net operating assets (scaled by lagged total assets) is a strong negative predictor of stock returns. We define the scaled net operating assets, denoted NOA, as $\left(O A_{t}-O L_{t}\right) / T A_{t-1}$ in which $O A_{t}$ is operating assets calculated as total assets (Compustat annual item 6) minus cash and shortterm investment (item 1). $O L_{t}$ is operating liabilities calculated as $T A_{t}-S T D_{t}-L T D_{t}-M I_{t}-$ $P S_{t}-C E_{t}$, in which $S T D_{t}$ is debt included in current liabilities (item 34 ), $L T D_{t}$ is long-term debt (item 9), $M I_{t}$ is minority interests (item 38), $P S_{t}$ is preferred stocks (item 130), and $C E_{t}$ is common equity (item 60). NOA is closely related to the comprehensive measure of accruals from Richardson, Sloan, Soliman, and Tuna (2005).

Without discussing the details, we note that from Tables A1 and A2 the impact of financial constraints on the investment-to-assets effect and the net operating assets effect are largely similar to the impact on the asset growth effect reported in Table 2 .

\section{A.2 Tests Using Failure Probability as a Measure of Financial Distress}

The failure probability ( $F$-prob) is from Campbell, Hilscher, and Szilagyi (2008). We construct $F$-prob following their paper (the third column in Table 4):

$$
\begin{gathered}
F-\operatorname{prob}(t)=-9.164-20.264 N I M T A A V G_{t}+1.416 T L M T A_{t}-7.129 \text { EXRETAVG }_{t} \\
+1.411 S I G M A_{t}-0.045 R S I Z E_{t}-2.132 \text { CASHMTA } A_{t}+0.075 M B_{t}-0.058 \text { PRICE }_{t}
\end{gathered}
$$

in which

$$
\begin{aligned}
& \text { NIMTAAVG } G_{t-1, t-12} \equiv \frac{1-\phi^{2}}{1-\phi^{12}}\left(\operatorname{NIMTA}_{t-1, t-3}+\cdots+\phi^{9} N \operatorname{IMT} A_{t-10, t-12}\right) \\
& \operatorname{EXRETAVG}_{t-1, t-12} \equiv \frac{1-\phi}{1-\phi^{12}}\left(\operatorname{EXRET}_{t-1}+\cdots+\phi^{11} \operatorname{EXRET}_{t-12}\right)
\end{aligned}
$$


The coefficient $\phi=2^{-1 / 3}$, meaning that the weight is halved each quarter. NIMTA is net income (COMPUSTAT quarterly item 69) divided by the sum of market equity and total liabilities (item 54). The moving average NIMTAAVG is designed to capture the idea that a long history of losses is a better predictor of bankruptcy than one large quarterly loss in a single month. EXRET $\equiv \log \left(1+R_{i t}\right)-\log \left(1+R_{\mathrm{S} \& \mathrm{P} 500, t}\right)$ is the monthly $\log$ excess return on each firm's equity relative to the $\mathrm{S} \& \mathrm{P} 500$ index. The moving average $E X R E T A V G$ is designed to capture the idea that a sustained decline in stock market value is a better predictor of bankruptcy than a sudden stock price decline in a single month. TLMTA is the ratio of total liabilities divided by the sum of market equity and total liabilities. SIGMA is the volatility of each firm's daily stock return over the past three months. RSIZE is the relative size of each firm measured as the log ratio of its market equity to that of the $\mathrm{S} \& \mathrm{P} 500$ index. CASHMTA, used to capture the liquidity position of the firm, is the ratio of cash and short-term investments divided by the sum of market equity and total liabilities. $M B$ is the market-to-book equity. PRICE is the log price per share of the firm. Because of the data limitation of total liabilities (Compustat quarterly item 54), the sample period for the $F$-prob related tests is from July 1976 to December 2006.

Table A3 reports the asset growth, net stock issues, and accrual effects across subsamples split by the failure probability measure from Campbell, Hilscher, and Szilagyi (2008). The results are largely similar to those in Table 5. Table A4 uses failure probability to evaluate the robustness of the horse race results reported in Table 6 . The measures of financial constraints have explanatory power for the net stock issues effect, and the explanatory power is largely comparable with that of failure probability. A similar pattern also holds for the asset growth and accrual portfolios. In all, the evidence suggests that the effect of financial constraints is distinct from that of financial distress. 
Table A1 : The Investment-to-Assets Effect Across Subsamples Split by Payout Ratio, Bond Rating, and the Whited-Wu $(W W)$ Index

In June of each year $t$, we split the sample into three equal-numbered subsamples by payout ratio (Panel A), two subsamples by bond ratings (Panel B), and three equal-numbered subsamples by the $W W$ index (Panel C), all measured at the end of fiscal year $t-1$. In Panels A and B, the sample is from July 1963 to December 2006 (534 months). In Panel C, the sample is from July 1976 to December 2006 (378 months) because of the quarterly data limitation for long-term debt in the construction of the $W W$ index. Payout ratio is defined as the sum of dividends and stock repurchase divided by operating income. In Panel B, the constrained subsample contains all the firms with debt outstanding but without a bond rating, and the unconstrained subsample contains all the firms whose bonds are rated. See Section 3 for details of constructing the $W W$ index. Within each subsample, we sort firms into five equal-numbered portfolios based on investment-to-assets (I/A) defined as the sum of annual change in property, plant, and equipment (Compustat annual item 7) and annual change in inventories (item 3) divided by lagged total assets (item 6). The high-minus-low portfolio (H-L I/A) is long in the high I/A portfolio and short in the low I/A portfolio. Portfolio returns are computed from July of year $t$ to June of year $t+1$. The portfolios are rebalanced at the end of each June. Excess return $(r)$ is the difference between portfolio returns and the one-month Treasury bill rate. The CAPM alphas $(\alpha)$ and Fama-French alphas $\left(\alpha_{F F}\right)$ are the intercepts from regressing portfolio excess returns on the market factor and the three Fama-French factors, respectively. The superscript ew denotes equal-weighted returns and $v w$ denotes value-weighted returns. The $t$-statistics, $t_{\mathrm{H}-\mathrm{L}}$, are adjusted for heteroscedasticity and autocorrelations.

\begin{tabular}{|c|c|c|c|c|c|c|c|c|c|c|c|c|c|c|c|c|c|c|}
\hline & \multicolumn{6}{|c|}{ Panel A: Subsamples by payout ratio } & \multicolumn{6}{|c|}{ Panel B: Subsamples by bond rating } & \multicolumn{6}{|c|}{ Panel C: Subsamples by the $W W$ index } \\
\hline & \multicolumn{6}{|c|}{ Low payout ratio (most constrained) } & \multicolumn{6}{|c|}{ With bond rating (unconstrained) } & \multicolumn{6}{|c|}{ Low $W W$ (least constrained) } \\
\hline & $r^{e w}$ & $\alpha^{e w}$ & $\alpha_{F F}^{e w}$ & $r^{v w}$ & $\alpha^{v w}$ & $\alpha_{F F}^{v w}$ & $r^{e w}$ & $\alpha^{e w}$ & $\alpha_{F F}^{e w}$ & $r^{v w}$ & $\alpha^{v w}$ & $\alpha_{F F}^{v w}$ & $r^{e w}$ & $\alpha^{e w}$ & $\alpha_{F F}^{e w}$ & $r^{v w}$ & $\alpha^{v w}$ & $\alpha_{F F}^{v w}$ \\
\hline Low & 1.52 & 0.90 & 0.47 & 0.74 & 0.03 & -0.19 & 1.34 & 0.82 & 0.46 & 0.71 & 0.24 & 0.10 & 0.87 & 0.25 & -0.14 & 0.66 & 0.07 & -0.03 \\
\hline 2 & 1.44 & 0.81 & 0.50 & 0.71 & 0.04 & & 1.04 & 0.54 & 0.31 & 0.53 & 0.10 & & 0.78 & 0.20 & & 0.64 & 0.08 & 0.10 \\
\hline 3 & 1.14 & 0.49 & 0.23 & 0.73 & 0.01 & 0 . & 0.90 & 0.41 & 0.21 & 0.42 & 0.02 & & 0.80 & 0.24 & & 0.57 & 0.03 & 0.11 \\
\hline 4 & 0.89 & 0.23 & 0.00 & 0.39 & -0.34 & -0.08 & 0.86 & 0.35 & & 0.38 & -0.09 & & 0.69 & 0.08 & & 0.47 & -0.19 & -0.06 \\
\hline High & 0.32 & -0.37 & -0.61 & 0.18 & -0.58 & -0.31 & 0.64 & 0.04 & -0.16 & 0.38 & -0.17 & -0.04 & 0.48 & -0.21 & -0.44 & 0.40 & -0.29 & -0.16 \\
\hline $\begin{array}{l}\mathrm{H}-\mathrm{L} \mathrm{I} / \mathrm{A} \\
t_{\mathrm{H}-\mathrm{L}}\end{array}$ & $\begin{array}{l}-1.20 \\
-7.77\end{array}$ & $\begin{array}{l}-1.27 \\
-8.41\end{array}$ & $\begin{array}{l}-1.08 \\
-7.40\end{array}$ & $\begin{array}{l}-0.57 \\
-2.72\end{array}$ & $\begin{array}{l}-0.61 \\
-2.94\end{array}$ & $\begin{array}{l}-0.12 \\
-0.62\end{array}$ & $\begin{array}{l}-0.70 \\
-6.01\end{array}$ & $\begin{array}{l}-0.78 \\
-6.91\end{array}$ & $\begin{array}{l}-0.62 \\
-5.61\end{array}$ & $\begin{array}{l}-0.33 \\
-2.64\end{array}$ & $\begin{array}{l}-0.41 \\
-3.32\end{array}$ & $\begin{array}{l}-0.14 \\
-1.22\end{array}$ & $\begin{array}{l}-0.39 \\
-3.59\end{array}$ & $\begin{array}{l}-0.46 \\
-4.18\end{array}$ & & $\begin{array}{l}-0.26 \\
-1.84\end{array}$ & $\begin{array}{l}-0.36 \\
-2.55\end{array}$ & $\begin{array}{l}-0.13 \\
-0.92\end{array}$ \\
\hline \multirow{2}{*}{$t_{\mathrm{H}-\mathrm{L}}$} & \multicolumn{6}{|c|}{ High payout ratio (least constrained) } & \multicolumn{6}{|c|}{ Without bond rating (constrained) } & \multicolumn{6}{|c|}{ High $W W$ (most constrained) } \\
\hline & $r^{e w}$ & $\alpha^{e w}$ & $\alpha_{F F}^{e w}$ & $r^{v w}$ & $\alpha^{v w}$ & $\alpha_{F F}^{v w}$ & $r^{e w}$ & $\alpha^{e w}$ & $\alpha_{F F}^{e w}$ & $r^{v w}$ & $\alpha^{v w}$ & $\alpha_{F F}^{v w}$ & $r^{e w}$ & $\alpha^{e w}$ & $\alpha_{F F}^{e w}$ & $r^{v w}$ & $\alpha^{v w}$ & $\alpha_{F F}^{v w}$ \\
\hline Low & 1.15 & 0.68 & 0. & 0 & & & 1.40 & 0.86 & & 0 . & 6 & - & 1.81 & 1.12 & & .65 & & -0.29 \\
\hline 2 & 0.84 & 0.40 & 0.10 & 0.54 & & & 1.19 & 0.68 & & 0 . & & & 1.82 & 1.14 & & 0.70 & & -0.13 \\
\hline 3 & 0.77 & 0.35 & 0.10 & 0.46 & 7 & & 0.94 & 0.43 & & & & & 1.49 & 0.80 & & 22 & & -0.25 \\
\hline 4 & 0.74 & 0.31 & 0. & & & & 0.73 & 0.19 & -0 & & & & 1.26 & 0.58 & & 0.66 & & -0.13 \\
\hline High & 0.57 & 0.09 & -0.22 & 0.43 & -0.03 & -0.02 & 0.29 & -0.30 & -0.64 & -0.05 & -0.69 & -0.64 & 0.61 & -0.08 & -0.34 & 0.22 & -0.64 & -0.63 \\
\hline$t_{\mathrm{H}-\mathrm{L}}$ & \multicolumn{6}{|c|}{ Low-minus-high payout ratio } & \multicolumn{6}{|c|}{ Without-minus-with bond rating } & \multicolumn{6}{|c|}{ High-minus-low $W W$} \\
\hline $\mathrm{H}-\mathrm{L} \mathrm{I} / \mathrm{A}$ & -0.62 & -0.68 & -0.55 & -0.26 & -0.30 & -0.00 & -0.41 & -0.38 & -0.47 & -0.31 & -0.34 & -0.35 & -0.81 & -0.74 & -0.85 & -0.17 & -0.14 & -0.21 \\
\hline$t_{\mathrm{H}-\mathrm{L}}$ & -3.88 & -4.36 & -3.64 & -1.16 & -1.33 & -0.11 & -4.33 & -4.08 & -5.16 & -2.81 & -3.10 & & -4.52 & -4.14 & & -0.75 & & -0.91 \\
\hline
\end{tabular}


Table A2 : The Net Operating Assets Effect Across Subsamples Split by Payout Ratio, Bond Rating, and the Whited-Wu $(W W)$ Index

In June of each year $t$, we split the sample into three equal-numbered subsamples by payout ratio (Panel A), two subsamples by bond ratings (Panel B), and three equal-numbered subsamples by the $W W$ index (Panel C), all measured at the end of fiscal year $t-1$. In Panels A and B, the sample is from July 1963 to December 2006 (534 months). In Panel C, the sample is from July 1976 to December 2006 (378 months) because of the quarterly data limitation for long-term debt in the construction of the $W W$ index. Payout ratio is defined as the sum of dividends and stock repurchase divided by operating income. In Panel B, the constrained subsample contains all the firms with debt outstanding but without a bond rating, and the unconstrained subsample contains all the firms whose bonds are rated. See Section 3 for details of constructing the $W W$ index. Within each subsample, we sort firms into five equal-numbered portfolios based on net operating assets (NOA). See Appendix A.1 for detailed variable definition of NOA. The high-minus-low portfolio (H-L NOA) is long in the high NOA portfolio and short in the low NOA portfolio. Portfolio returns are computed from July of year $t$ to June of year $t+1$. The portfolios are rebalanced at the end of each June. Excess return $(r)$ is the difference between portfolio returns and the one-month Treasury bill rate. The CAPM alphas $(\alpha)$ and Fama-French alphas $\left(\alpha_{F F}\right)$ are the intercepts from regressing portfolio excess returns on the market factor and the three Fama-French factors, respectively. The superscript $e w$ denotes equal-weighted returns and $v w$ denotes value-weighted returns. The $t$-statistics, $t_{\mathrm{H}-\mathrm{L}}$, are adjusted for heteroscedasticity and autocorrelations.

\begin{tabular}{|c|c|c|c|c|c|c|c|c|c|c|c|c|c|c|c|c|c|c|}
\hline & \multicolumn{6}{|c|}{ Panel A: Subsamples by payout ratio } & \multicolumn{6}{|c|}{ Panel B: Subsamples by bond rating } & \multicolumn{6}{|c|}{ Panel C: Subsamples by the $W W$ index } \\
\hline & \multicolumn{6}{|c|}{ Low payout ratio (most constrained) } & \multicolumn{6}{|c|}{ With bond rating (unconstrained) } & \multicolumn{6}{|c|}{ Low $W W$ (least constrained) } \\
\hline & $r^{e w}$ & $\alpha^{e w}$ & $\alpha_{F F}^{e w}$ & $r^{v w}$ & $\alpha^{v w}$ & $\alpha_{F F}^{v w}$ & $r^{e w}$ & $\alpha^{e w}$ & $\alpha_{F F}^{e w}$ & $r^{v w}$ & $\alpha^{v w}$ & $\alpha_{F F}^{v w}$ & $r^{e w}$ & $\alpha^{e w}$ & $\alpha_{F F}^{e w}$ & $r^{v w}$ & $\alpha^{v w}$ & $\alpha_{F F}^{v w}$ \\
\hline Low & 1.41 & 0.71 & 0.49 & 0.65 & -0.09 & 0.04 & 1.29 & 0.72 & 0.63 & 0.53 & 0.00 & 0.26 & 0.95 & 0.28 & 0.11 & 0.74 & 0.10 & 0.25 \\
\hline 2 & 1.42 & 0.75 & 0.44 & 0.83 & 0.09 & 0.17 & 1.09 & 0.55 & 0.32 & 0.55 & 0.10 & 0.16 & 0.88 & 0.29 & -0.08 & 0.62 & 0.09 & -0.03 \\
\hline 3 & 1.28 & 0.65 & 0.29 & 0.63 & -0.10 & 0.05 & 1.02 & 0.51 & 0.23 & 0.52 & 0.08 & 0.12 & 0.63 & 0.10 & -0.15 & 0.45 & -0.07 & -0.04 \\
\hline 4 & 0.95 & 0.34 & 0.02 & 0.54 & -0.16 & -0.03 & 0.86 & 0.34 & 0.05 & 0.35 & -0.12 & -0.12 & 0.87 & 0.26 & -0.15 & 0.55 & -0.06 & -0.18 \\
\hline High & 0.37 & -0.30 & -0.59 & 0.20 & -0.55 & -0.36 & 0.65 & 0.06 & -0.19 & 0.30 & -0.22 & -0.14 & 0.53 & -0.20 & -0.48 & 0.39 & -0.32 & -0.27 \\
\hline $\mathrm{H}-\mathrm{L}$ NOA & -1.04 & -1.01 & -1.09 & -0.45 & -0.46 & -0.41 & -0.64 & -0.66 & -0.81 & -0.22 & -0.22 & -0.40 & -0.50 & -0.54 & -0.63 & -0.44 & -0.48 & -0.53 \\
\hline \multirow[t]{3}{*}{$t_{\mathrm{H}-\mathrm{L}}$} & -5.60 & -5.58 & -5.90 & -2.01 & -2.11 & -1.76 & -4.12 & -4.34 & -5.37 & -1.69 & -1.69 & -2.95 & -5.10 & -5.59 & -6.12 & -3.60 & -4.06 & -4.05 \\
\hline & \multicolumn{6}{|c|}{ High payout ratio (least constrained) } & \multicolumn{6}{|c|}{ Without bond rating (constrained) } & \multicolumn{6}{|c|}{ High $W W$ (most constrained) } \\
\hline & $r^{e w}$ & $\alpha^{e w}$ & $\alpha_{F F}^{e w}$ & $r^{v w}$ & $\alpha^{v w}$ & $\alpha_{F F}^{v w}$ & $r^{e w}$ & $\alpha^{e w}$ & $\alpha_{F F}^{e w}$ & $r^{v w}$ & $\alpha^{v w}$ & $\alpha_{F F}^{v w}$ & $r^{e w}$ & $\alpha^{e w}$ & $\alpha_{F F}^{e w}$ & $r^{v w}$ & $\alpha^{v w}$ & $\alpha_{F F}^{v w}$ \\
\hline Low & 1.02 & 0.53 & $\overline{0.34}$ & 0.59 & 0.11 & 0.23 & 1.25 & 0.65 & $\overline{0.41}$ & 0.43 & -0.19 & -0.09 & 1.90 & 1.08 & 0.89 & 0.63 & -0.30 & -0.23 \\
\hline 2 & 0.95 & 0.48 & 0.20 & 0.51 & 0.07 & 0.09 & 1.21 & 0.68 & 0.33 & 0.56 & 0.04 & -0.02 & 1.77 & 0.92 & 0.34 & 0.65 & -0.33 & -0.73 \\
\hline 3 & 0.91 & 0.45 & 0.12 & 0.53 & 0.11 & 0.10 & 1.06 & 0.55 & 0.16 & 0.35 & -0.16 & -0.25 & 1.58 & 0.93 & 0.61 & 0.71 & -0.10 & -0.12 \\
\hline 4 & 0.77 & 0.31 & -0.03 & 0.43 & -0.02 & -0.11 & 0.76 & 0.26 & -0.11 & 0.37 & -0.15 & -0.27 & 1.33 & 0.72 & 0.47 & 0.77 & 0.03 & -0.04 \\
\hline High & 0.55 & 0.07 & -0.26 & 0.31 & -0.12 & -0.21 & 0.26 & -0.30 & -0.66 & -0.19 & -0.82 & -0.79 & 0.65 & 0.00 & -0.34 & 0.04 & -0.75 & -0.87 \\
\hline $\mathrm{H}-\mathrm{L}$ NOA & -0.47 & -0.46 & -0.60 & -0.27 & -0.23 & -0.44 & -0.99 & -0.95 & -1.07 & -0.62 & -0.63 & -0.70 & -1.25 & -1.07 & -1.23 & -0.59 & -0.46 & -0.63 \\
\hline \multirow[t]{2}{*}{$t_{\mathrm{H}-\mathrm{L}}$} & -6.15 & -6.08 & -8.00 & -2.16 & -1.84 & -3.58 & -6.42 & -6.37 & -7.14 & -3.64 & -3.77 & -3.84 & -4.84 & -4.48 & -5.21 & -2.17 & -1.75 & -2.47 \\
\hline & \multicolumn{6}{|c|}{ Low-minus-high payout ratio } & \multicolumn{6}{|c|}{ Without-minus-with bond rating } & \multicolumn{6}{|c|}{ High-minus-low $W W$} \\
\hline $\mathrm{H}-\mathrm{L} \mathrm{NOA}$ & -0.57 & -0.55 & -0.49 & -0.17 & -0.23 & 0.04 & -0.34 & -0.28 & -0.26 & -0.40 & -0.41 & -0.30 & -0.75 & -0.54 & -0.60 & -0.15 & 0.03 & -0.11 \\
\hline$t_{\mathrm{H}-\mathrm{L}}$ & -3.29 & -3.23 & -2.76 & -0.73 & -0.98 & 0.15 & -3.30 & -2.81 & -2.46 & -2.14 & -2.23 & -1.54 & -3.07 & -2.40 & -2.77 & -0.52 & 0.10 & -0.39 \\
\hline
\end{tabular}


Table A3 : The Asset Growth, Net Stock Issues, and Accrual Effects Across Subsamples Split by Failure Probability ( $F$-prob) (July 1976-December 2006, 378 Months)

At the end of June of year $t$, we first split the sample into three equal-numbered subsamples by $F$-prob measured in fiscal year ending in calendar year $t-1$. The definition of F-prob is described in Section 3. Within each subsample, firms are sorted into five equal-numbered portfolios based on asset growth (AG, Panel A), net stock issues (NS, Panel B), and accruals (AC, Panel C). AG is the change in total assets divided by lagged total assets. NS is the change in the natural logarithms of the number of shares outstanding adjusted for splits to capture the effect of share repurchases and seasoned equity offerings. AC is the changes in non-cash working capital minus depreciation expense scaled by average total assets in the recent two years. Portfolio returns are computed over the period from July of year $t$ to June of year $t+1$. The portfolios are rebalanced at the end of each June. Excess return $(r)$ is the difference between portfolio returns and the one-month Treasury bill rate. The CAPM alphas $(\alpha)$ and Fama-French alphas $\left(\alpha_{F F}\right)$ are the intercepts from regressing portfolio excess returns on the market factor and the three Fama-French factors, respectively. The superscript $e w$ denotes equal-weighted returns and $v w$ denotes value-weighted returns. The $t$-statistics are adjusted for heteroscedasticity and autocorrelation.

\begin{tabular}{|c|c|c|c|c|c|c|c|c|c|c|c|c|c|c|c|c|c|c|}
\hline & \multicolumn{6}{|c|}{ Panel A: Asset growth (AG) } & \multicolumn{6}{|c|}{ Panel B: Net stock issues (NS) } & \multicolumn{6}{|c|}{ Panel C: Accruals (AC) } \\
\hline & \multicolumn{6}{|c|}{ Low $F$-prob (least distressed) } & \multicolumn{6}{|c|}{ Low $F$-prob (least distressed) } & \multicolumn{6}{|c|}{ Low $F$-prob (least distressed) } \\
\hline & $r^{e w}$ & $\alpha^{e w}$ & $\alpha_{F F}^{e w}$ & $r^{v w}$ & $\alpha^{v w}$ & $\alpha_{F F}^{v w}$ & $r^{e w}$ & $\alpha^{e w}$ & $\alpha_{F F}^{e w}$ & $r^{v w}$ & $\alpha^{v w}$ & $\alpha_{F F}^{v w}$ & $r^{e w}$ & $\alpha^{e w}$ & $\alpha_{F F}^{e w}$ & $r^{v w}$ & $\alpha^{v w}$ & $\alpha_{F F}^{v w}$ \\
\hline Low & 1.10 & 0.50 & 0.20 & 0.69 & 0.14 & -0.01 & 1.04 & 0.52 & 0.22 & 0.82 & 0.30 & 0.27 & 1.01 & 0.35 & 0.10 & 0.53 & -0.10 & 0.01 \\
\hline 2 & 0.90 & 0.38 & 0.07 & 0.64 & 0.16 & & 0.86 & 0.35 & -0.03 & 0.59 & 0.10 & & 0.96 & 0.36 & 0.10 & 0.58 & 0.04 & 0.00 \\
\hline 3 & 0.87 & 0.31 & 0.08 & 0.52 & -0.03 & -0.06 & 0.86 & 0.25 & 0.01 & 0.43 & -0.14 & -0.14 & 0.84 & 0.24 & 0.00 & 0.60 & 0.04 & 0.07 \\
\hline 4 & 0.88 & 0.23 & 0.04 & 0.64 & 0.03 & 0.21 & 0.88 & 0.19 & 0.03 & 0.63 & -0.03 & 0.03 & 0.77 & 0.15 & -0.07 & 0.36 & -0.22 & -0.16 \\
\hline High & 0.41 & -0.37 & -0.52 & 0.31 & -0.40 & -0.29 & 0.52 & -0.25 & -0.37 & 0.24 & -0.39 & -0.36 & 0.66 & -0.06 & -0.28 & 0.32 & -0.45 & -0.31 \\
\hline $\mathrm{H}-\mathrm{L}$ & -0.69 & -0.87 & -0.71 & -0.38 & -0.54 & -0.28 & .52 & -0.78 & -0.59 & -0.58 & -0.69 & -0.64 & 0.35 & -0.41 & -0.38 & -0.21 & -0.35 & -0.32 \\
\hline \multirow[t]{3}{*}{$t_{\mathrm{H}-\mathrm{L}}$} & -5.11 & -7.41 & -5.96 & -2.27 & -3.43 & -2.02 & -2.93 & -5.15 & -4.45 & -3.84 & -4.65 & -4.44 & -3.63 & -4.56 & -4.05 & -1.07 & -1.84 & -1.73 \\
\hline & \multicolumn{6}{|c|}{ High $F$-prob (most distressed) } & \multicolumn{6}{|c|}{ High $F$-prob (most distressed) } & \multicolumn{6}{|c|}{ High $F$-prob (most distressed) } \\
\hline & $r^{e w}$ & $\alpha^{e w}$ & $\alpha_{F F}^{e w}$ & $r^{v w}$ & $\alpha^{v w}$ & $\alpha_{F F}^{v w}$ & $r^{e w}$ & $\alpha^{e w}$ & $\alpha_{F F}^{e w}$ & $r^{v w}$ & $\alpha^{v w}$ & $\overline{\alpha_{F F}^{v w}}$ & $r^{e w}$ & $\alpha^{e w}$ & $\alpha_{F F}^{e w}$ & $r^{v w}$ & $\alpha^{v w}$ & $\alpha_{F F}^{v w}$ \\
\hline Low & 2.09 & 1.30 & 0.97 & 0.75 & -0.10 & -0.19 & 1.79 & 1.18 & $\overline{0.76}$ & 1.06 & 0.34 & 03 & 1.69 & 0.88 & $\overline{0.58}$ & 0.49 & -0.37 & -0.32 \\
\hline 2 & 1.73 & 1.05 & 0.65 & 1.16 & 0.42 & 0.26 & 1.62 & 0.98 & 0.5 & 0.79 & 0.13 & -0.16 & 1.46 & 0.77 & 0.4 & 0.48 & -0.35 & -0.39 \\
\hline 3 & 1.42 & 0.77 & 0.41 & 0.95 & 0.27 & 0.07 & 1.28 & 0.54 & 0.27 & 0.88 & 0.15 & 0.11 & 1.35 & 0.66 & 0.31 & 0.75 & 0.00 & 0.08 \\
\hline 4 & 1.02 & 0.34 & 0.02 & 0.54 & -0.22 & -0.07 & 1.15 & 0.33 & 0.13 & 0.61 & -0.32 & -0.11 & 1.17 & 0.45 & 0.15 & 0.74 & -0.08 & 0.13 \\
\hline High & 0.30 & -0.53 & -0.66 & 0.24 & -0.65 & -0.36 & 0.64 & -0.18 & -0.33 & -0.02 & -0.87 & -0.69 & 0.86 & 0.08 & -0.16 & 0.18 & -0.77 & -0.53 \\
\hline \multirow[t]{2}{*}{$t_{\mathrm{H}-\mathrm{L}}$} & -7.79 & -8.22 & -7.32 & -1.83 & -1.95 & -0.59 & -5.67 & -7.04 & -6.33 & -3.89 & -4.49 & -3.55 & -4.83 & -4.83 & -4.59 & -1.12 & -1.43 & -0.71 \\
\hline & \multicolumn{6}{|c|}{ High-minus-low $F$-prob } & \multicolumn{6}{|c|}{ High-minus-low $F$-prob } & \multicolumn{6}{|c|}{ High-minus-low $F$-prob } \\
\hline $\mathrm{H}-\mathrm{L}$ & -1.09 & -0.96 & -0.92 & -0.13 & -0.01 & 0.12 & -0.63 & -0.57 & -0.50 & -0.50 & -0.53 & -0.37 & -0.48 & -0.40 & -0.36 & -0.11 & -0.05 & 0.12 \\
\hline$t_{\mathrm{H}-\mathrm{L}}$ & -5.24 & -4.87 & -4.95 & -0.43 & -0.01 & 0.42 & -4.21 & -3.91 & -3.22 & -1.74 & -1.86 & -1.25 & -2.49 & -2.14 & -2.03 & -0.36 & -0.15 & 0.34 \\
\hline
\end{tabular}


Table A4 : The Asset Growth, Net Stock Issues, and Accrual Effects Across Subsamples Split by Payout Ratio/Bond Rating/the Whited-Wu ( $W W$ ) Index and Failure Probability (F-prob) (July 1976-December 2006, 378 Months)

On June 30 of year $t$, we split the sample into six subsamples by an independent three-by-two sort on payout ratio and $F$-prob (Panel A) and on the $W W$ index and F-prob (Panel C). In Panel B, we split the sample into four subsamples by an independent two-by-two sort on bond rating and $F$-prob. The sort on bond rating categorizes firms into two groups: the constrained group containing the firms with debt outstanding but without a bond rating and the unconstrained group containing the firms whose bonds are rated. All the sorting variables are measured in fiscal year ending in calendar year $t-1$. The definition of $F$-prob is described in Section 3 . Within each subsample, firms are further sorted into five equal-numbered portfolios based on asset growth (AG), net stock issues (NS), and accruals (AC). Portfolio returns are computed over the period from July of year $t$ to June of year $t+1$. The portfolios are rebalanced at the end of each June. Excess return $(r)$ is the difference between portfolio returns and the onemonth T-bill rate. The CAPM alphas $(\alpha)$ and Fama-French alphas $\left(\alpha_{F F}\right)$ are the intercepts from regressing portfolio excess returns on the market factor and the Fama-French factors, respectively. The superscripts $e w$ and $v w$ denote equal-weighted and value-weighted returns, respectively. Statistics significant at the $5 \%$ level are denoted with *.

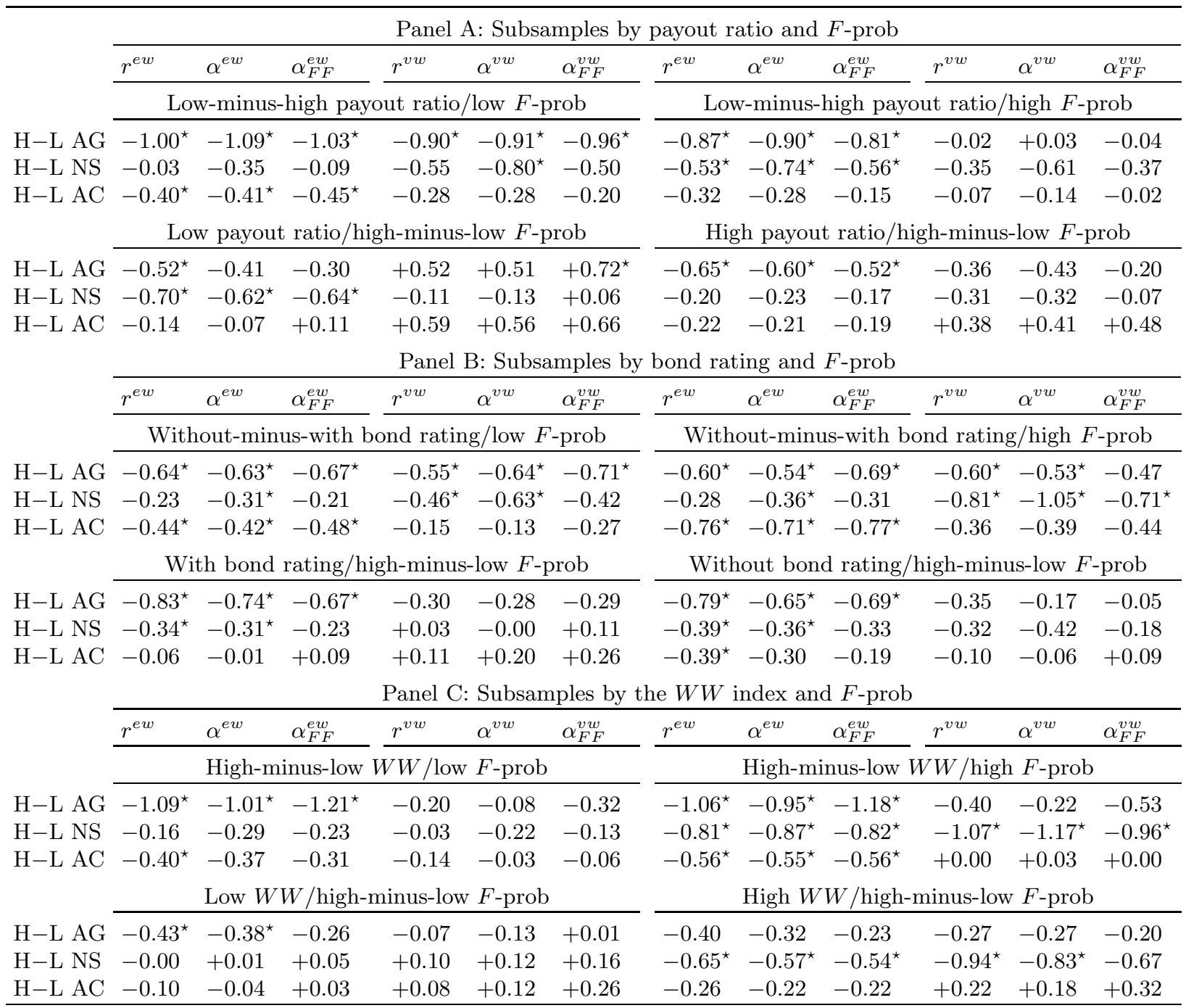

